\title{
ELECTROANALYTICAL OPPORTUNITIES DERIVED FROM ION TRANSFER AT INTERFACES BETWEEN IMMISCIBLE ELECTROLYTE SOLUTIONS
}

Damien W. M. Arrigan, ${ }^{*}$ Eva Alvarez de Eulate and Yang Liu

Nanochemistry Research Institute \& Department of Chemistry, Curtin University, GPO Box U1987, Perth, Western Australia, Australia, 6845.

*E: d.arrigan@curtin.edu.au,Phone+61-8-92669735, Twitter@arri_aus

\section{Summary}

This review presents an introduction to electrochemistry at interfaces between immiscible electrolyte solutions and surveys recent studies of this form of electrochemistry in electroanalytical strategies. Simple ion and facilitated ion transfers across interfaces varying from millimetre scale to nanometre scales are considered. Target detection strategies for a range of ions, inorganic, organic and biological, including macromolecules, are discussed.

\section{Introduction}

Interfacial ion-transfer reactions are an important sub-set of chemical processes which have tremendous importance in biology, materials, industry, engineering, etc., for example, in the establishment of membrane potentials, the partitioning of drug candidates between phases and across membranes, the extraction of metals, and the purification of waters. The transfer of ions across the interface between immiscible liquids or between liquids and membrane phases is a widely studied and exploited transformation. The foundation of electroanalytical detection methods on iontransfers can be established in a similar manner to methods based on oxidation or reduction processes occurring at the surface of electrodes. While potentiometric ion-partitioning devices have been widely studied (i.e. membrane ion-selective electrodes), dynamic electroanalytical methods at liquid-liquid interfaces have been less actively pursued. However, in recent years, there has been considerable expansion of interest in this area, with electrochemistry at liquid-liquid interface ${ }^{[1]}$ now the subject of investigations for a range of analytical and bioanalytical problems, ${ }^{[2]}$ spanning nonredox detection of inorganic ions ${ }^{[3]}$ to behaviour and separations of biological macromolecules. ${ }^{[4]}$ The 
focus of this review is to introduce the key principles of this form of dynamic electrochemistry and to discuss its recent achievements and progress in analytical chemistry.

Electrochemical methods have found wide-ranging applications in modern society, ranging from $\mathrm{pH}$ determinations with glass membrane ion-selective electrodes, conductivity measurements for water purity and chromatographic detection, detection of blood electrolytes by ion-selective electrodes, through to measurements of blood glucose concentrations using enzyme-based amperometric biosensors. From a chemical detection and sensing perspective, electrochemical methods offer the scope for low-cost and easily-portable analytical systems that can be applied to chemical, biochemical and even microbiological applications. Often, the key requirement is that there is an easily oxidisable or reducible substance present that can couple reactions of the target analyte to the electrode. When target species are not easily oxidised or reduced, or their reactions are not easily coupled with electrode processes, then electrochemical methods may not be the best detection strategy. However, the use of electrochemical methods at liquid-liquid interfaces (oil-water interfaces) enables the detection of ionised species that are not easily oxidised or reduced or whose redox chemistry has associated complications. The key attraction of this form of electrochemistry is that it does not depend on the redox properties of a target solute but rather on the ion-transfer capability, as governed by the ions' Gibbs energies of transfer for a particular water-organic solvent system. Accordingly, ions can be transferred across the interface between suitable aqueous and organic electrolyte phases by choice of the imposed interfacial potential difference. This potential difference can be applied via suitable electrodes immersed in the bulk phases, and the current can be measured as a function of that applied potential. Thus, current-applied potential curves (voltammograms) can be constructed and thermodynamic, kinetic and analytical information such as transfer potentials, association constants, diffusion coefficients, and limits of detection can be determined for simple and facilitated ion transfer reactions. This review article provides a summary of the principles of electrochemistry at liquid-liquid interfaces and reviews recent progress in the exploration of analytical opportunities derived from this form of dynamic electrochemistry.

\section{Physicochemical principles $^{[1-2]}$}

When two immiscible solutions of electrolyte are brought into contact, the behaviour of the interface formed depends on the ions present in both phases. If the two electrolyte solutions, i.e. a water phase $(w)$ with dissolved electrolyte, and an organic phase (o) with dissolved electrolyte, share a 
common ion species, $i$, the equilibrium distribution across the interface of the common ion will lead to the establishment of an equilibrium potential difference, described by the equations

$$
\begin{aligned}
& \Delta_{\mathrm{o}}^{\mathrm{w}} \phi=\Delta_{\mathrm{o}}^{\mathrm{w}} \phi_{i}^{\circ}+\frac{\mathrm{RT}}{z_{i} \mathrm{~F}} \ln \left(\frac{a_{i}^{o}}{a_{i}^{w}}\right) \\
& \Delta_{o}^{\mathrm{w}} \phi=\Delta_{\mathrm{o}}^{\mathrm{w}} \phi_{i}^{\circ}+\frac{\mathrm{RT}}{z_{i} \mathrm{~F}} \ln \left(\frac{c_{i}^{o}}{c_{i}^{w}}\right)
\end{aligned}
$$

in which $\Delta_{o}^{\mathrm{w}} \phi$ is the imposed Galvani potential difference between the two immiscible phases, $\Delta_{o}^{\mathrm{w}} \phi_{i}^{\circ}$ is the standard transfer potential of the ion species $i, \Delta_{\mathrm{o}}^{\mathrm{w}} \phi_{i}^{\circ \prime}$ is the formal transfer potential of ion $i$, $z_{i}$ is its charge, $\mathrm{R}, \mathrm{T}$ and $\mathrm{F}$ are the universal gas constant, temperature and Faraday's constant, respectively, while $a_{i}^{o}, a_{i}^{w}, c_{i}^{o}, c_{i}^{w}$ are the activities $(a)$ or concentrations $(c)$ of species $i$ in the organic (o) or water phases $(w)$.

These equations (Eq. 1a and 1b) are the forms of Nernst equation expressed for an interfacial liquidliquid ion transfer process, in terms of either activity or concentration of the ions. The interface in this case has a chemically-imposed potential difference across it whose magnitude can be altered by controlling the equilibrium ratio of ion activities (Eq. 1a) or concentrations (Eq. 1b). For example, if tetraethylammonium chloride (TEACl) is dissolved in the aqueous phase, and tetraethylammonium tetraphenylborate (TEATPB) in the organic phase, distribution of the tetraethylammonium ions $\left(\mathrm{TEA}^{+}\right)$across the interface will lead to a potential difference that may be tuned by changing the concentration ratio according to Eq. $1 \mathrm{~b}$ (provided none of the other ions present participate in transinterface equilibria). The standard transfer potential of ion $i \Delta_{\mathrm{o}}^{\mathrm{w}} \phi_{i}^{\circ}$ in eq. $1 \mathrm{a}$ is related to the formal transfer potential $\Delta_{\mathrm{o}}^{\mathrm{w}} \phi_{i}^{\circ \prime}$ by the activity coefficients of the ions in each phase. The standard transfer potential is related to the Gibbs energy of transfer of the ion between the two respective phases, according to the expression

$$
\Delta_{\mathrm{o}}^{\mathrm{w}} \phi_{i}^{\circ}=\frac{\Delta G_{t r}^{\circ} \mathrm{w} \rightarrow \mathrm{o}}{z_{i} \mathrm{~F}}
$$

where $\Delta G_{t r,}^{\circ}, \mathrm{w} \rightarrow \mathrm{o}$ is the Gibbs energy of transfer of ion $i$ between the two phases which, in turn, reflects the differences in the solvation energies of the ion in the aqueous and organic phases.

Accordingly, ions with different molecular properties will possess different solvation and transfer energies and therefore have different standard transfer potentials. For example, the standard transfer potentials of caesium $\left(\mathrm{Cs}^{+}\right)$, tetraethylammonium $\left(\mathrm{TEA}^{+}\right)$and perchlorate $\left(\mathrm{ClO}_{4}^{-}\right)$between water and nitrobenzene (NB) are $0.363 \mathrm{~V}, 0.019 \mathrm{~V}$ and $-0.17 \mathrm{~V}$, respectively. As a result, bringing 
aqueous and NB phases containing equimolar activities of these ions into contact will establish interfacial potential differences set by the these standard potentials. Thus, three W|NB ITIES can be established, with three different interfacial potential differences, and each one is defined by the properties of the potential-determining ion according to Eq. 1. As stated above, further manipulation of the interfacial potential difference established can be achieved by changing the ratio of the ion concentrations in W and NB phases. Clearly, chemistry can be used to impose a potential difference across the ITIES.

In contrast, if two immiscible phases that contain no common ion species are brought into contact, there is no distribution of a common ion across the interface and no establishment of a stable potential difference. For example, solutions of aqueous lithium chloride ( $\mathrm{LiCl}$ ) and NB containing tetrabutylammonium tetraphenylborate (TBATPB) have no common ion that can establish the stable potential difference. In this case, the interface is said to be polarisable because an external power source, such as an electrochemical potentiostat, can be used to impose instrumentally a potential difference via electrodes placed in the respective phases. In this way, the aqueous-phase can be made more positive or negative relative to the NB phase and, by use of the electrochemical instrument, the applied potential difference can be changed gradually between values of greater or lesser potential difference. That is, potentiodynamic (potential scanning) experiments can be implemented and the potential difference across the liquid-liquid interface can be controlled in a similar way to that of a solid electrode in a conventional electrochemical cell. The resultant currenttime or current-potential curves can be recorded and the assortment of current-potential-time measurements that are implemented at solid electrodes can also be used at the ITIES.

The two interfaces discussed above can be written in electrochemical notation as follows:

$$
\begin{gathered}
\text { TEACl }_{w} \mid \text { TEATPB }_{N B} \\
\text { LiCl }_{w} \mid \text { TBATPB }_{N B}
\end{gathered}
$$

where the subscript W and NB indicate the aqueous or organic (nitrobenzene) phases, and the vertical bar represents the interface. In the first case, the concentration ratio of the common ion establishes a potential difference, and in the second case there is no common ion and there is no stable potential difference originating from the chemical composition of the phases. Instead, this second interface can be polarised using an external power source, and the potential difference can be imposed via a couple of electrodes, one placed on each side of the interface. Such interfaces are 
referred to as non-polarisable and polarisable, respectively, in a similar manner to non-polarisable and ideally polarisable electrodes, meaning that external imposition of a potential difference will or will not change, respectively, the chemical composition of the phases adjacent to the interfaces via passage of an electrical current.

\section{Interfacial structure \& kinetics $^{[2 a, 5]}$}

When two immiscible electrolyte phases are brought into contact and a potential difference is imposed across the interface, the ions of the electrolytes respond by formation of electrical double layers on both sides of the interface. The structure of the ITIES has been subject to many studies over the years. ${ }^{[1-2,5]}$ Such back-to-back electrical double layers have ion distributions that change with the applied potential difference, and hence give rise to a charging, or capacitive, current that varies with the applied potential difference. From an electroanalytical perspective, this imposes a significant background current signal that must be factored into the design of new sensors and detection methods using electrochemistry at the ITIES. Nevertheless, the interface has been studied by a variety of experimental and computational approaches. The results of molecular dynamics (MD) simulations by Benjamin ${ }^{[6]}$ indicated that while the aqueous - organic interface was molecularly sharp, it comprised of capillary waves (undulations, corrugation) in which fingers of one phase protruded into the other. This is in contrast to earlier studies ${ }^{[5 a]}$ which summarised the liquid-liquid interface as a three-phase system, in which an ion-free mixed solvent (aqueous + organic) phase was located between the two bulk liquids. Neutron reflectivity and $\mathrm{x}$-ray reflectivity measurements have been used to elucidate the structure of the interface. For example, neutron reflectance combined with the molecular dynamics simulations indicate that the time-averaged interfacial thickness is of the order of $1 \mathrm{~nm}$, but that ions present greatly influence the local structure. X-ray reflectivity studies of the ITIES determined the interfacial thickness to be in the range of $0.6-0.8 \mathrm{~nm}$ for $\mathrm{W} \mid \mathrm{NB}$ and $\mathrm{W}$ |1,2-dichloroethane interfaces. Further discussions of the structure of the interface is available in Dryfe's recent review. ${ }^{[5 b]}$

Much of the recent interest in electrochemistry at the ITIES has been aimed at examining the kinetics of interfacial ion and electron transfer reactions. Simple ion transfer reactions and facilitated ion transfer reactions have generally been regarded as reversible (fast) and display diffusion-controlled features, which is the reaction-type used in most analytical systems. The kinetics of ion transfer remains an area of active study and is related intimately to the structure of the interface summarised 
above. As discussed in a number of reviews, ${ }^{[2 a, 5 a, 7]}$ the formation of digital protrusions of one phase into the other may aid ion transfer reactions, by serving as a means to initiate desolvation/solvation processes. Key challenges in the study of ion transfer kinetics at the ITIES have been the minimisation of the impact of the organic phase resistance and enhancing of mass transport rates, ${ }^{[5 a]}$ which lead to the development of micro- and nano-interfaces. ${ }^{[8]}$ However as discussed by Dryfe ${ }^{[5 b]}$ and by Samec, ${ }^{[5 a]}$ there seems to be a dependence of determined ion transfer rate constant on year of reporting, and in turn on the improved methods used for the determinations. Hence, establishment of the true values of ion transfer kinetics remains the subject of on-going studies. ${ }^{[8 b, 8 c]}$

\section{Experimental systems}

For electroanalytical experiments at the ITIES, the key piece of information is that the potential difference can be imposed across the interface using a suitable set of electrodes, and current can be measured as a function of potential, or time, or both. This enables the application at the ITIES of electroanalytical methods ranging from chronoamperometry and cyclic voltammetry through to pulsed and square wave voltammetry and electrochemical impedance spectroscopy to study and make use of ion transfer processes.

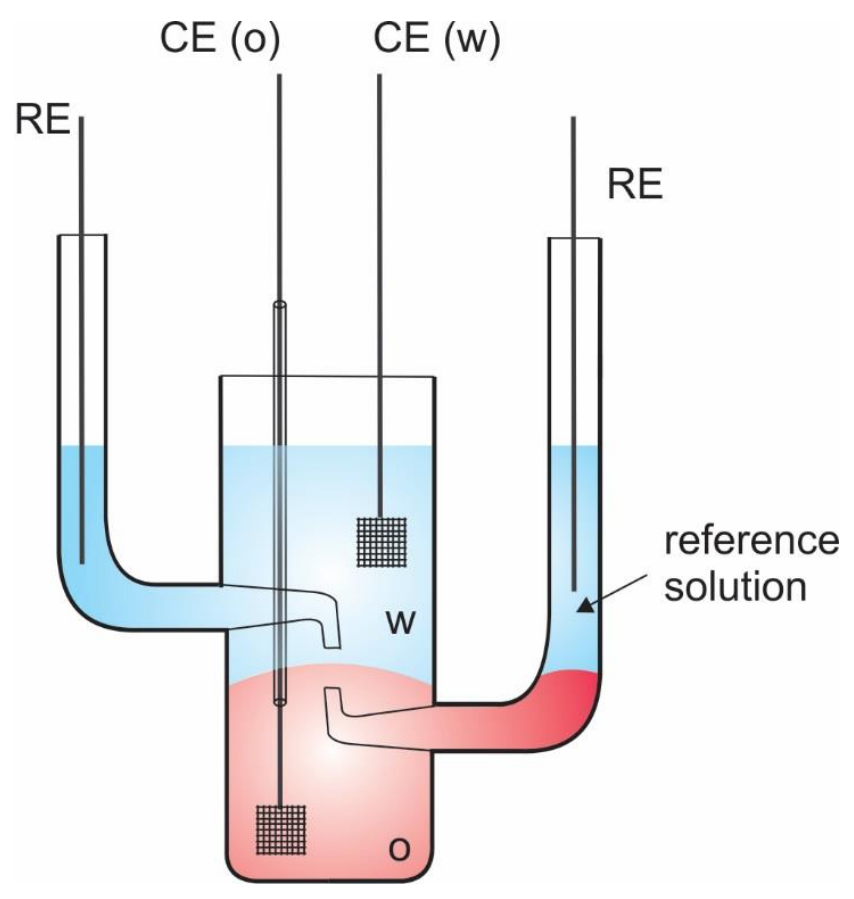

Figure 1. Diagram of the electrochemical cell used for macro-ITIES studies. 
A typical cell set-up for electrochemistry at the ITIES (Figure 1) contains the two electrolyte phases ( $w$ and o), two reference electrodes (RE, to enable the potential difference to be monitored) and two counter electrodes ( $C E$, to enable the current to be measured). The electrodes are arranged so that one reference electrode and one counter electrode are present in each phase. The cell voltage is controlled by the pair of the reference electrodes, whose sensitivity to the solution close to the interface is ensured by the use of two Luggin capillaries. The two counter electrodes are platinum flag or mesh electrodes, which can be separated from the solutions by a glass frit, preventing any products of electrochemical reactions that occur at the counter electrodes from contaminating the solutions. ${ }^{[9]}$ Control and measurement is achieved via a four-electrode potentiostat. ${ }^{[10]}$ Nowadays, the major electrochemical instrument companies all supply potentiostats that can be used for these measurements, with the reference and counter electrode terminals and "sense" and "working" electrode terminals used to form the reference/counter pair for each electrolyte phase, respectively. Such four-electrode arrangements are used normally only when the ITIES is considered 'large', i.e. has dimensions of ca. $1 \mathrm{~cm}^{2}-1 \mathrm{~mm}^{2}$ in geometric area, so that the large resistance of the organic phase can be compensated and reliable measurements made. The cell shown in Figure 1 illustrates such a typical four-electrode cell and voltammetry of the ITIES in these systems is frequently used for characterisation of new chemical systems but generally not for development of methods to detect low $(\leq 10 \mu \mathrm{M})$ concentrations.

The composition of each electrolyte phase is highly important from an experimental viewpoint, as this enables the setting of a reasonable 'potential window' within which the transfer of target charged analytes (or solutes) can be observed. Accordingly, the aqueous phase will contain a dissolved electrolyte comprised of hydrophilic ions. Typically, this will be lithium chloride or lithium sulphate, and in turn the aqueous phase reference electrode chemistry is chosen to match the aqueous electrolyte phase. The hydrophilic nature of the ions present means that they do not partition into the adjacent organic phase, and that they can be transferred to the organic phase only when an adequate potential (dependent on their Gibbs energy of transfer) is imposed via the electrode system. Thus lithium cations will transfer at a positive potential value, while sulphate anions will transfer at a negative applied potential. ${ }^{[11]}$ The opposite characteristics are required of ions forming the organic electrolyte. The solvent in this case is usually a polar organic solvent such as NB, 1,2-dichloroethane (DCE), 1,6-dichlorohexane (DCH), ${ }^{[12]}$ o-nitrophenyloctylether (NPOE); new solvents suitable for studies at the ITIES are regularly reported. ${ }^{[13]}$ The electrolytes in this phase are 
comprised of hydrophobic cations and anions, such as alkylammonium cations and tetraphenylborate anions. Longer alkyl chain alkylammonium cations are better, as they will be more difficult to transfer to the aqueous phase, while tetraphenylborate anions with chloro- or fluorofunctionality on the phenyl rings are better as these are more hydrophobic and more difficult to transfer to the aqueous phase. Table 1 lists some typical constituents used to establish the ITIES for electrochemical studies.

Table 1. Common electrolyte solution constituents.

\begin{tabular}{|c|c|c|c|c|}
\hline \multicolumn{2}{|c|}{ Organic solvents } & \multicolumn{2}{|c|}{ Organic phase electrolyte } & \multirow{2}{*}{$\begin{array}{c}\text { Aqueous phase } \\
\text { electrolyte }\end{array}$} \\
\hline Acronym & Chemical structure & Acronym & Chemical structure & \\
\hline NB & & BTPPATPBCl & & $\mathrm{LiCl}$ \\
\hline NPOE & & BTPPATPBF & & $\mathrm{HCl}$ \\
\hline DCE & $\mathrm{ClCH}_{2} \mathrm{CH}_{2} \mathrm{Cl}$ & & & $\mathrm{Li}_{2} \mathrm{SO}_{4}$ \\
\hline DCH & $\mathrm{ClCH}_{2}\left(\mathrm{CH}_{2}\right)_{4} \mathrm{CH}_{2} \mathrm{Cl}$ & (ETH500) & & $\mathrm{H}_{2} \mathrm{SO}_{4}$ \\
\hline
\end{tabular}

BTPPA: bis(triphenylphosphoranylidene)

TPBCl: tetrakis(4-chlorophenyl)borate

TPBF: tetrakis(4-fluorophenyl)borate

TDA: tetradocecylammonium

ETH500 is the product name for this commercially available salt also commony used in potentiometricion selective electrodes.

The final component of the cell is, of course, the electrode system chosen. The aqueous electrolyte solution usually dictates the chemistry of the aqueous reference electrode used, hence a chloride salt will be used in conjunction with a silver/silver chloride wire directly immersed in the aqueous phase. If a sulphate salt is used as the aqueous phase, then a silver/silver sulphate wire can be used 
to form the reference electrode. ${ }^{[14]}$ In the organic phase, a suitable electrode can be immersed directly, such as a silver wire coated with an insoluble salt of silver with the anion of the organic electrolyte, e.g. Ag/AgTPB. ${ }^{[15]}$ Such electrode systems can be replaced with a simple silver wire immersed in the organic phase, giving a pseudo-reference electrode, which may be unstable, or a $\mathrm{Ag} / \mathrm{AgCl}$ electrode connected to the organic phase via an additional aqueous phase (Fig. 1), containing chloride but also a salt of the anion present in the organic phase. This introduces an additional liquidliquid interface into the cell, but in this case the interface is non-polarisable because the two phases share a common ion (the anion of the organic phase electrolyte). Combining all of this information into a cell used to study electrochemistry at the ITIES will produce a cell composition such as shown in Scheme 1.

Ag $|\mathrm{AgCl}| \operatorname{LiCl}(10 \mathrm{mM})_{\mathrm{w}}$, TEACl(0.1 mM) ||BTPPATPBCl(10 mM)o|BTPPACl(1 mM), LiCl(10 mM)|AgCl|Ag

Scheme 1: Typical electrochemical cell composition.

In this cell, a series of non-polarisable interfaces (denoted by the single vertical bar |) and a single polarisable interface (denoted by the double vertical bars ||) are present. It is the chemistry of the latter interface that is of interest in electrochemistry at the ITIES.

A

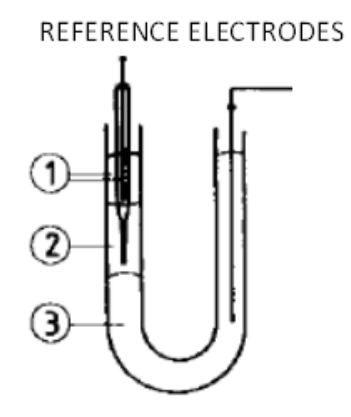

B

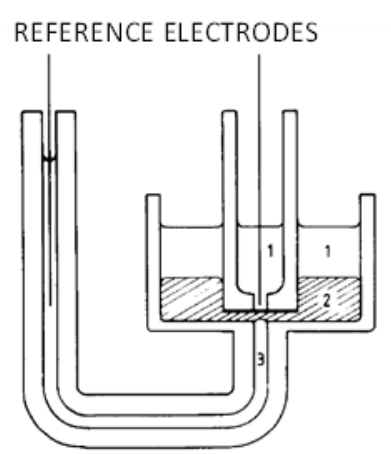

C

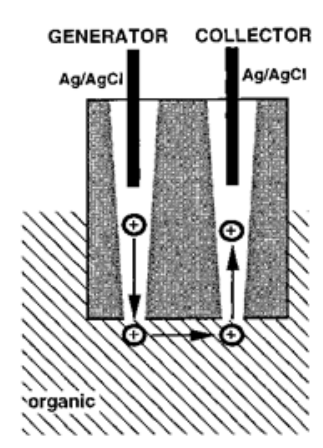

Figure 2. Electrochemical cells for ITIES at a micropipette (A), a microhole in a thin polymer film (B) and a dual micropipette (C): 1) Aqueous electrolyte; 2) Organic electrolyte; 3) Organic reference electrolyte. Reproduced with permission from (A) J. Electroanal. Chem. 1986, 208, 179, ${ }^{[16]}$ copyright 1986 Elsevier, (B) J. Electroanal. Chem. 1989, 266, 465, ${ }^{[17]}$ copyright 1989 Elsevier; and (C) J. Am. Chem. Soc. 1998, 120, 12700, ${ }^{[18]}$ copyright 1998 American Chemical Society. 
The so-called 'macro-ITIES' cells (Fig. 1) have been widely used for the characterisation of ions or ionisable compounds such as drugs, ${ }^{[19]}$ amino acids, ${ }^{[20]}$ proteins, $^{[21]}$ and DNA. ${ }^{[22]}$ The use of electrochemical methods at the macro-ITIES has been shown to be powerful for exploration of electrocatalysis $^{[23]}$ and the basis of spectrochemical analysis, ${ }^{[24]}$ as well as investigation of the behaviours of inorganic ions and biomolecules at liquid-liquid interfaces. ${ }^{[7,25]}$ For example, Hartvig et $a l^{[21 a]}$ studied the interaction between lysozyme and two lipophilic ions at the oil-water interface using cyclic voltammetry and electrochemical impedance spectroscopy at such a macro-ITIES. Su et al. ${ }^{[23 a]}$ reported molecular electrocatalysis for oxygen reduction at a water-DCE interface, which combined the use of molecular catalysts and electrochemistry at the ITIES. Matsui et al. ${ }^{\text {[21d] }}$ demonstrated label-free detection of albumin using amperometry at such a water-DCE interface, with an anionic surfactant present in the DCE phase. The macro-ITIES provided a basis for the development of new electrochemical sensing platforms, but the impact of mechanical instability of the ITIES combined with Ohmic (iR) drop and double-layer charging can be severe and mitigate against development of more sensitive analytical approaches. ${ }^{[25 c]}$

From an experimental viewpoint, the miniaturisation of the ITIES to microscale and to nanoscale, as with trends in other areas of modern electrochemistry, has brought many benefits, such as decreasing the impact of Ohmic drop and capacitive current, as well as enabling a more mechanicallystable ITIES to be formed. In particular, the decrease in current at a micro-interface has enabled simplification of the electrochemical instrumentation by employing a two-electrode arrangement. Miniaturisation also, of course, decreases the amount of solvents and supporting electrolytes employed. In 1986, Taylor and Girault ${ }^{[16]}$ introduced the micro-ITIES formed at the tip of a micropipette with an internal diameter of $25 \mu \mathrm{m}$ (Figure 2A). The immiscible phases meet, ideally, at the mouth of the pipette, to form a single microlTIES whose dimensions are governed by the size of the micropipette. They investigated the transfer of TEA ${ }^{+}$from the organic phase to the aqueous phase at the micro-interface. It was demonstrated that a spherical mass transfer pattern can be formed when the ions were transferred from outside the micropipette to inside the pipette, which produced high steady-state conditions of mass transport. Later, another approach to fabricate micro-ITIES was developed, based on formation of a microhole in inert polymer membranes (Figure 2B) by UV laser ablation. ${ }^{[17]}$ In this case, the polymer film containing a single microhole was placed between the two immiscible phases; the two liquid phases are in contact only at the microhole location, so that the ITIES formed has the geometric characteristics of the microhole. Over the subsequent decades, great 
efforts were made to explore ion transfer processes at the micro-ITIES, more often formed at the tip of a micropipette ${ }^{[16,26]}$ or within a microhole in a thin membrane. ${ }^{[26 a, 27]}$ Shao et al. ${ }^{[18,28]}$ developed a dual-micropipette micro-ITIES device for investigation of heterogeneous ion transfer reactions accompanied by homogeneous chemical reactions of ions in solution based on an electrochemical generation/collection method (Figure 2C). This approach enabled quantitative separation of simultaneous ion transfer processes occurring at the ITIES, so that the potential window limitations for investigation of many important reactions occurring at high positive and negative potentials were overcome. From an electroanalytical perspective, and as will be discussed in more detail below, because single or dual micro-ITIES produce low signal intensities (currents), arrays of microinterfaces, in which a number of individual interfaces are arranged in parallel, were developed to increase the electrochemical signals. ${ }^{[29]}$ Girault and co-workers used the laser ablation technique to prepare arrays of microholes in polymer membranes, ${ }^{[17]}$ at which micro-ITIES arrays were formed, while Arrigan and co-workers developed arrays of micro-ITIES formed at microporous silicon membranes, ${ }^{[29 a]}$ which were fabricated by lithographic patterning and wet and dry silicon etching processes. The micro-ITIES arrays exhibited improved analytical performances for detection of a wide range of analytes, such as metal ions, ${ }^{[30]}$ neurotransmitters, ${ }^{[31]}$ peptides ${ }^{[32]}$ and drugs. ${ }^{[33]}$

Further miniaturisation of the ITIES to nanoscale (Fig. 3A) can bring additional benefits, such as additional enhancement of mass transport, decrease of double layer charging currents, increase of the current density and decrease of Ohmic drop effects. ${ }^{[34]}$ With the rapid development of nanotechnology, many approaches to fabricate nanometre-sized devices were envisaged. These included laser-based pipette pulling, ${ }^{[35]}$ electron beam lithography (EBL) combined with chemical etching ${ }^{[36]}$ and focused ion beam (FIB) milling, ${ }^{[37]}$ all of which can be employed to form nano-orifices as a location for the ITIES. Over the last decade, many research groups have explored the electrochemical properties and applications of nanopipette-based nano-ITIES. For example, Laforge et al. ${ }^{[35 a]}$ described an electrochemical attosyringe based on a nano-ITIES formed at a nanopipette tip with an aperture ca. $300 \mathrm{~nm}$ radius. It was found that the fluid motion inside the nanopipette was controlled electrochemically, and this was used to inject fluorescent dyes into human breast epithelial cells. Due to the high mass transport effects resulting from convergent (radial) diffusion to nano-ITIES, they have become a standard platform for the investigation of ion transfer kinetics. For example, Li et al. ${ }^{[38]}$ studied the kinetics of ion transfer at a water-1,2-DCE interface using nanopipette steady-state voltammetry, and interpreted the steady-state current for the ion egress 
reaction at the nano-ITIES using two theoretical models. Nanopipette-based ITIES also offer the prospect of high resolution electrochemical imaging when used in scanning electrochemical microscopy (SECM). Shen et al. ${ }^{[39]}$ demonstrated high-resolution SECM for quantitative imaging of ion transport through single nanopores in a silicon membrane using a scanning nanopipette-based ITIES with a tip radius of $17 \mathrm{~nm}$. In this case, the nanopipette-based ITIES is the probe that is scanned across a surface to image its properties. This approach allowed the determination of structural properties of the nanopores, including their density, shape and size, and provided a basis for understanding the permeability of nanoporous membranes. In addition, arrays of nano-ITIES were developed for the investigation of electrochemical behaviour and detection of ions such as TEA ${ }^{+},[36$, ${ }^{40]}$ tetrapropylammonium $\left(\operatorname{TPrA}^{+}\right)^{[37 a, 41]}$ and protonated propranolol. ${ }^{[42]}$ These nanolTIES arrays were formed by placing nanoporous membranes, such as silicon nitride perforated with EBL-patterned nanopores, at the interface. Since the silicon nitride is naturally hydrophobic, the organic electrolyte fills the pores, enabling the formation of nanoITIES at the mouths of the pores. Similar types of nanopore membranes can be prepared by FIB milling, which enables a more flexible investigation of array patterns and layout. ${ }^{[37]}$

Generally, the benefits of miniaturised interfaces (microscale and nanoscale) over the macro-ITIES at regular (i.e. typically $\mathrm{mm}-\mathrm{cm}$ ) scales are greater mass transport effects, decreased capacitance, and lower influence of the uncompensated resistance via the iR drop. Besides that, probably just as important is an easier experimental handling of the interfaces, as an array of micro- or nano-ITIES can be treated essentially as a sensor device (e.g. see Figure 3B) that can be placed into different sample solutions for experimental evaluations. As a result, these miniaturised interface arrays have been often explored as the basis for ion sensors, while single microlTIES or nanoITIES, based on micropipettes or nanopipettes, are usually employed in studies of ion-transfer kinetics.

A

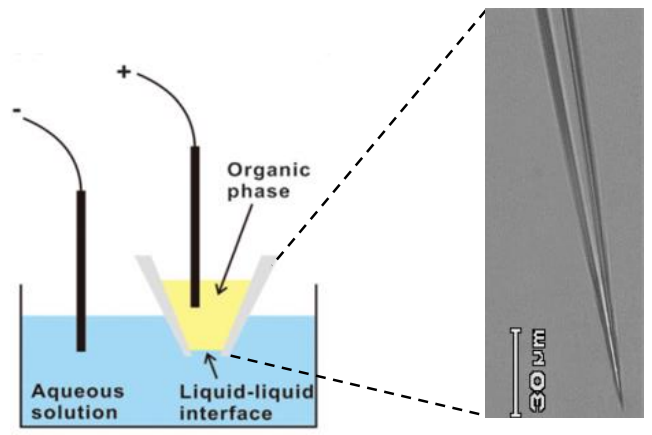

B

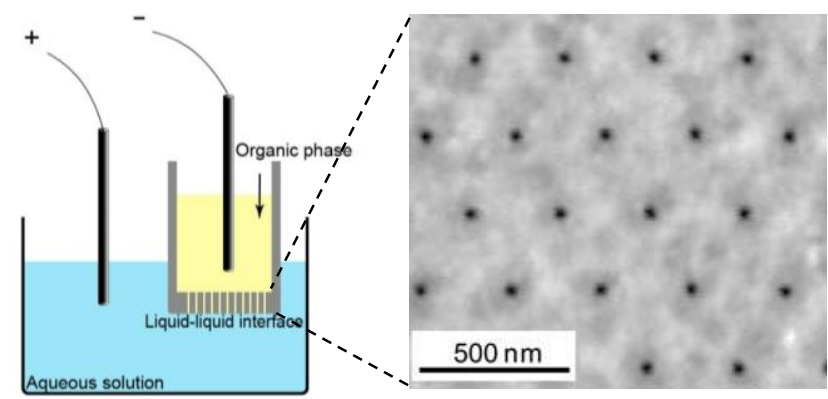


Figure 3. Electrochemical cells for ITIES at a nanopipette (radius $<10 \mathrm{~nm}$ ) $(A)$ and a nanoporous membrane. The image in A and B are reproduced with permission from Chem. Sci., 2011, 2, 1523, [43] copyright 2011 Royal Society of Chemistry, from Analyst, 2011, 136, 4674, ${ }^{[40]}$ copyright 2011 Royal Society of Chemistry, respectively).

Another platform for the establishment of the ITIES for electroanalytical studies is the thin film approaches have been established to form robust, supported ITIES, for ion sensor applications. Although in these cases the interface remains on the order of millimetres in scale, thin film behaviour exhibited certain advantages. These are an efficient diffusion of the analyte in the thin film and the total, exhaustive expulsion from the film when used in a stripping voltammetry format. Such behaviour is similar to that of the thin film mercury electrode used in anodic stripping voltammetry. ${ }^{[44]}$ For example, PVC-NPOE spin-coated films of $\sim 0.7$ to $1.3 \mu \mathrm{m}$ thickness have been reported by Amemiya's group onto electropolymerized electrodes. ${ }^{[45]}$ In this instance, the substrate electrode is modified electrochemically to introduce a thin conductive polymer which serves as an ion-to-electron transducer between the PVC-NPOE thin film and the electrode. This approach was further studied with a ca. $0.3 \mu \mathrm{m}$ thin film by Crespo et $a l^{[46]}$ in order to evaluate its selectivity capabilities. In a similar approach, this group has implemented thin films of aqueous liquids trapped between organic membrane phases for exhaustive electrolysis for heparin detection. ${ }^{[47]}$ In this approach, a small aliquot $(\sim 5 \mu \mathrm{L})$ of the sample is confined in a tubular polymeric selective membrane (polyether ether ketone (PEEK) tubing doped with dinonylnapthalene sulfonate (DNNS), tetradodecylammonium chloride and NPOE).

\section{Electrochemical methods}

The varied methods of dynamic (non-equilibrium) electrochemistry, such as voltammetry, chronoamperometry, chronopotentiometry and impedance spectrometry, can all be implemented at the ITIES. Some examples of experimental results are shown in Figure 4. Cyclic voltammetry (CV), widely used to explore electrode reaction mechanisms at solid electrodes, is also widely used at the ITIES. Figure 4a shows a CV for the transfer of TEA ${ }^{+}$between aqueous and DCE phases. In this case the interface is large, of ca. $1.8 \mathrm{~cm}$ diameter, and hence the transferring ions experience linear diffusion to the interface once a concentration gradient is established. The forward transfer current 
(positive current attributed to cation transfer from aqueous to organic phase) ${ }^{[1]}$ exhibits a peakshaped response, as does the reverse scan, with a negative current indicating the transfer of a cation from the organic phase to the aqueous phase. Since linear diffusion control occurs in such an experiment, the peak current is expected to vary with both the concentration of the transferring TEA ${ }^{+}$ cation and with the square root of the potential sweep rate, as encapsulated in the Randles-Sevcik equation,

$$
I_{p}=\left(2.69 \cdot 10^{5}\right) z_{i}^{3 / 2} A D_{i}^{1 / 2} C_{i} v^{1 / 2}
$$

where $I_{p}$ is the peak current for the transfer from aqueous phase to organic phase, $z_{i}$ is the charge on species $i, D_{i}$ is the diffusion coefficient of species $i$ in the aqueous phase, $C_{i}$ is the concentration of species $i$ in the aqueous phase, and $v$ is the potential scan rate applied. Figure $4 b-c$ also illustrate the role of molecular properties on ion-transfer voltammetry, showing the effect of the sequential addition of $\mathrm{TPrA}^{+}$and tetramethylammonium $\left(\mathrm{TMA}^{+}\right)$to the original aqueous phase containing $\mathrm{TEA}^{+}$. $\mathrm{TPA}^{+}$addition results in a new pair of ion-transfer peaks at a lower potential than for TEA ${ }^{+}$. This indicates the lower Gibbs energy of transfer for $\mathrm{TPA}^{+}$and hence the lower transfer potential required to push this species across the ITIES. Similarly, when TMA ${ }^{+}$is added, a new pair of peaks is recorded at a higher potential, which are indicative of the larger energy requirement for movement of these more hydrophilic cations from the aqueous phase to the organic phase. The formal transfer potential for these three cations can be obtained from the mid-point potential, or the average of the forward and reverse peak potentials for each cation, and, after transposing to the Galvani potential scale, related directly to the 'formal' Gibbs energy of transfer between the two phases by equation 2 . Hence, CV at the ITIES is a powerful method to obtain information about the properties of ions that undergo simple ion transfer reactions. Use of Eq. 3 also enables determination of other parameters of the transferring species, such as its diffusion coefficient or its concentration. As will be shown below, CV at the ITIES can also be used to determine the properties of facilitated ion transfer reactions, such as complexation stoichiometry and stability constants. 

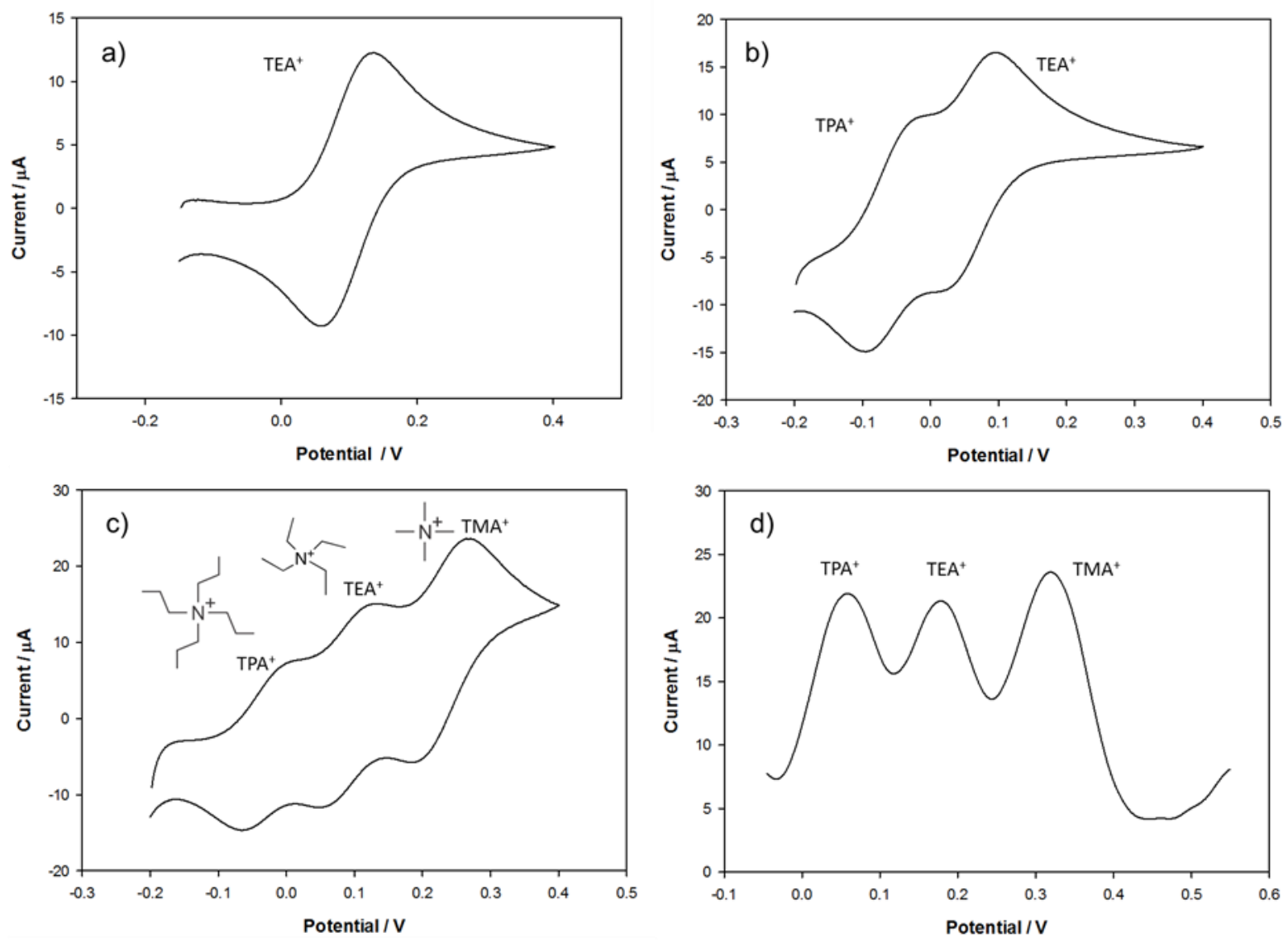

Figure 4. $\mathrm{CV}$ of a) $100 \mu \mathrm{M} \mathrm{TEACl}$, b) $100 \mu \mathrm{M} \mathrm{TEACl}+100 \mu \mathrm{M}$ TPACl and c) $100 \mu \mathrm{M}$ TPACl $+100 \mu \mathrm{M}$ TEACl $+100 \mu \mathrm{M}$ TPACl in $10 \mathrm{mM} \mathrm{LiCl}$. d) DPV of $100 \mu \mathrm{M} \mathrm{TPACl}+100 \mu \mathrm{M} \mathrm{TEACl}+100 \mu \mathrm{M}$ TPACl in 0.01 $\mathrm{M} \mathrm{LiCl}$ at macro-ITIES, interface area of $2.7 \mathrm{~cm}^{2}$, in 4-electrode cell mode. Both reference electrodes were $\mathrm{Ag} / \mathrm{AgCl}$. Organic phase was $10 \mathrm{mM}$ BTPPATPBCl in DCE in all cases. Scan rate for both $\mathrm{CV}$ and DPV: $10 \mathrm{mV} \mathrm{s}^{-1}$. Pulse parameter for DPV: $5 \mathrm{mV}$ step potential, $25 \mathrm{mV}$ pulse amplitude, $0.05 \mathrm{~s}$ pulse time and 0.5 s interval time.

Detection of lower concentrations than those possible with CV is achievable by application of pulsed voltammetric methods, such as differential pulse voltammetry (DPV). DPV of the mixture of TPrA ${ }^{+}$, $\mathrm{TEA}^{+}$and $\mathrm{TMA}^{+}$is shown in Figure $4 \mathrm{~d}$ and illustrates the improved resolution as well as the possibility of improved sensitivity that can be achieved by these pulsed methods relative to linear scan or staircase methods such as CV. As well be discussed below, DPV and related methods are often implemented at the ITIES or micro-ITIES to achieve lower detection limits. 


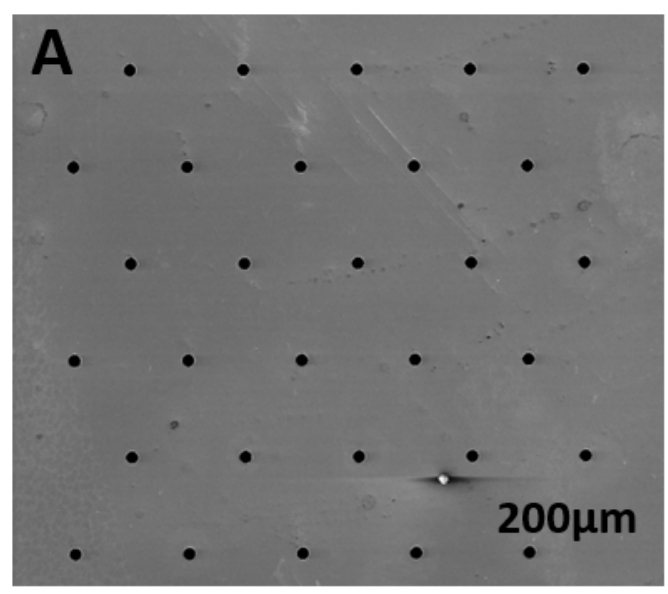

C

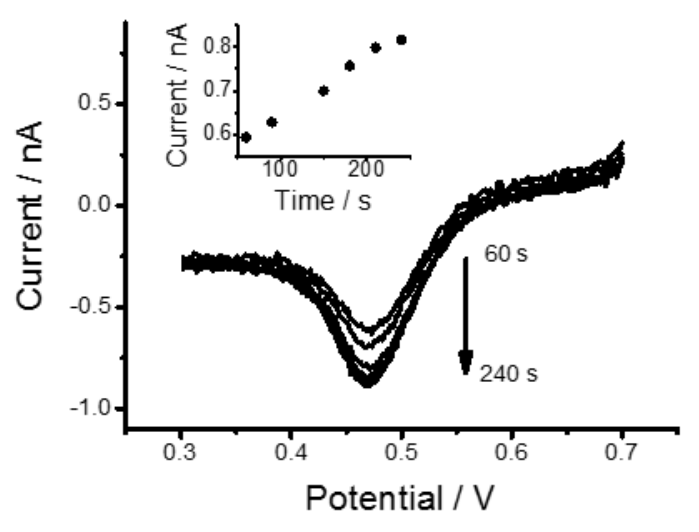

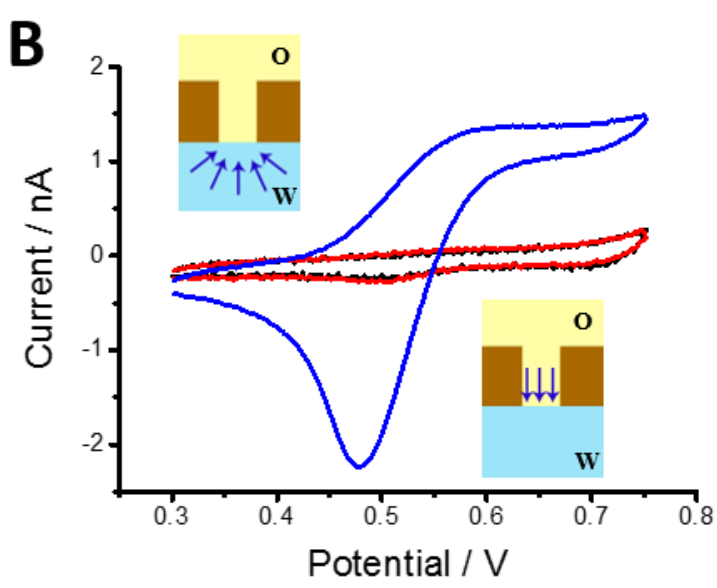

D

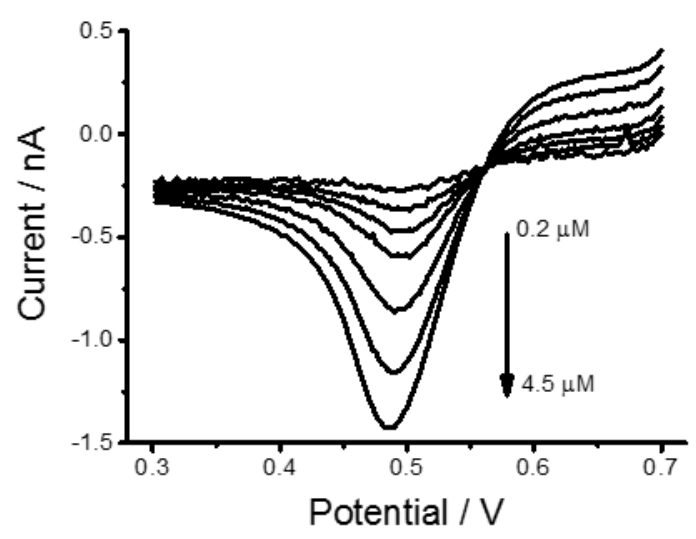

Figure 5. (A) SEM image of a micropore array used to form the micro-ITIES array. (B) Cyclic voltammograms of 0 (black), 0.2 (red) and $10 \mu \mathrm{M}$ (blue) TPrA ${ }^{+}$transfer across the micro-ITIES array $(d=22.65 \mu \mathrm{m} ; \mathrm{N}=30)$. (C) Linear sweep stripping voltammograms of $2 \mu \mathrm{M} \operatorname{TPrA}^{+}$at the micro-ITIES array following different preconcentration times $(60,90,150,180,210$ and $240 \mathrm{~s})$, sweep rate: $5 \mathrm{mV} / \mathrm{s}$. Inset shows the effect of the preconcentration time on the peak current. (D) Linear sweep stripping voltammograms of increasing $\operatorname{TPrA}^{+}$concentrations $(0.2,0.5,1,1.5,2.5,3.5$ and $4.5 \mu \mathrm{M})$ in $0.01 \mathrm{M} \mathrm{LiCl}$ solution at the micro-ITIES array, preconcentration time: $210 \mathrm{~s}$, sweep rate: $5 \mathrm{mV} / \mathrm{s}$.

Whereas the CVs of simple ion transfer reactions at the ITIES display the characteristic shapes that one can see at diffusion-controlled reactions at solid electrodes, at the microITIES (and to some extent the nanoITIES) and microITIES arrays, the CV response can be quite different. Figure 5A shows a silicon microporous membrane composed of an array of 30 pores each of radius $11.3 \mu \mathrm{m}$. Such a porous membrane can be used to pattern the ITIES and form a microlTIES array. A typical CV for a simple ion transfer reaction at this microlTIES array is shown in Figure 5B. In this case, the current 
due to the transfer of $\operatorname{TPrA}^{+}$from the aqueous phase to the organic phase (which is held in the micropores) is positive in value, but rather than being a peak shaped, it displays a steady-state voltammogram. This is indicative of the presence of a radial diffusion process at each micro-interface within the array (see inset sketch in Fig. 5B). The interfaces are formed the micropore mouths and the pores within the area are sufficiently separated from each other that the radial diffusion profiles that form at each micropore mouth are independent of their neighbours. In such a case, the steadystate current is simple the current obtained at a single microlTIES of identical dimensions multiplied by the number of interfaces in the array (in this case as defined by the number of micropores in the silicon membrane, 30). For an inlaid disc interface, such as those formed at the mouths of micropores, the steady-state current is described by the Saito equation, ${ }^{[48]}$

$$
I_{s s}=4\left|z_{i}\right| F D_{i} C_{i} r_{a}
$$

in which $I_{s s}$ is the steady-state current, $r_{a}$ is the radius of the microinterface (microdisc) and the other parameters are as previously defined. The current at the microinterface array is then this current multiplied by the number of independent interfaces in the array.

On the reverse scan of the CV (Figure 5B), however, the response shape is markedly different from the forward scan. In this case, a peak-shaped voltammogram is obtained. This is due to the reverse ion transfer process, from the organic phase held inside the micropores to the aqueous phase outside the pores, which is controlled by diffusion in the organic phase. Due to the constraints imposed by the pore walls, diffusion can occur only in one-dimension (see inset sketch in Fig. 5B), resulting in peak-shaped voltammograms (in the same way as CV at an ITIES produces peak-shaped voltammograms due to control by one-dimensional diffusion, Figure 4A). Hence, CV at microlTIES and microITIES arrays have an asymmetric diffusion profile - it is different on forward and reverse scans - and produce voltammograms with distinctive shapes determined by those diffusion profiles. Whether formed at an array of micropores in a silicon membrane, ${ }^{[29 a]}$ at an array of laser-ablated holes in a membrane, ${ }^{[49]}$ or at the mouth of a micropipette, ${ }^{[16]}$ the CVs can generally be useful for determination of the properties of the micro-interface, such as diffusion profile for forward and reverse transfer processes, and the location of the interface relative to the mouth of the orifice. Often, such experimental characterisation is performed in conjunction with computer simulations, in which diffusion processes and electrochemical ion transfer kinetics can be modelled and compared to the experimental observations. ${ }^{[49 b, 50]}$ 
Figure $5 \mathrm{C}$ shows a series of stripping voltammograms implemented at the microITIES array formed using the micropore array membrane shown in Figure 5A. In this case, the voltammograms were scanned from $+0.7 \mathrm{~V}$ to $+0.3 \mathrm{~V}$ after holding the applied potential at $+0.7 \mathrm{~V}$ for different times. Stripping voltammetry is a two-stage electroanalytical technique which can greatly enhance detection limits and analytical sensitivity. The first stage is the application of a constant applied potential during which (at the ITIES) an ion transfer process occurs to extract the target ion from the aqueous phase into the organic phase. This serves to preconcentrate the analyte so that the concentration during the subsequent (second stage) is higher than was naturally present in the original sample aqueous phase. During this second stage, the analyte is back-extracted from the organic phase to the aqueous phase, and the ion transfer current is much higher, due to the preconcentration stage, so that sensitivity and detection limits can be improved. In Figure 5C, at the initial constant applied potential, the ion transfer process of aqueous to organic transfer takes place, so that the analyte ion concentration in the organic phase increases with time. On the subsequent scan to lower potential, the analyte ions are back-extracted from the organic phase into the aqueous phase, and a current peak is recorded which is dependent on both the analyte concentration in the aqueous phase and the time during which the analyte was transferred to the organic phase. The power of this method is its two-step procedure: (i) the analyte is preconcentrated into the organic phase, and (ii) the analyte is stripped back into the aqueous phase using a suitable voltammetric method, such as LSV, DPV or SWV. By controlling the duration of the preconcentration step, more analyte can be transferred into the organic phase; furthermore, by controlling the analyte's diffusion coefficient in the organic phase, the analyte can be 'forced' to stay close to the interface and to be available for the stripping step; by controlling the geometry of the pores used to the form the microITIES, loss of the analyte from the interfacial region into the bulk organic phase can also be minimised. Thus the preconcentration time, gellification of the organic phase, and the pore geometry are important parameters to consider when designing a stripping voltammetry method at the microITIES. ${ }^{[51]}$ The voltammograms in Figure 5(D) show an increasing magnitude of stripping peak current as the ion concetration is increased and the preconcentration time is kept constant, illustrating the analytical sensitivity that is achievable with this approach. For example, detection of drugs such as propranolol at nanomolar levels using DPSV approaches at the microlTIES has been achieved, ${ }^{[52]}$ amongst other possible applications investigated. 


\section{Electroanalytical chemistry at the ITIES}

\section{Simple ion transfer (IT) reactions}

There has been much interest in simple IT reactions as any charged species can be transferred across the polarisable liquid-liquid interface when the required energy of transfer is reached via the applied potential difference within the limitations set by the transfer potentials of the background electrolyte ions. This transfer yields a current which can be measured independently of the target ion's redox activity. In this section, a series of recent studies towards new avenues in ion detection at the ITIES are examined, as previous publications have already covered an extensive part of this area of research. In 2012 Sanchez Vallejo et al. ${ }^{[53]}$ published an extensive review on simple ion transfer electrochemistry, in which they discussed an extensive list of ions studied at W/NB, W/DCE, W/NPOE and W/RTIL interfaces, as well as at other less commonly-studied water/oil interfaces. Additionally, numerous publications have reported thermodynamic and kinetic information $\left(\Delta G_{I}^{w \rightarrow o}, k^{0}, D_{I}^{w}\right),{ }^{[1,5 a]}$ about simple ion transfers, e.g. alkali metal ions, quaternary ammonium cations and common anions.

As discussed above, the transfer of three quaternary ammonium ions $\left(\mathrm{TMA}^{+}, \mathrm{TEA}^{+}\right.$and $\left.\operatorname{TPrA}^{+}\right)$at a W/DCE interface is presented in Figure 4. These analytes possess different alkyl chains (methyl-, ethyl- and propyl-) and as the alkyl chain length increases, the tetraalkylammonium ion becomes more hydrophobic. This is manifested as a lower Gibbs energy of transfer and hence transfer potential $\left(\Delta \phi_{T P A^{+}}^{w \rightarrow O^{+}}<\Delta \phi_{T E A^{+}}^{w \rightarrow o^{+}}<\Delta \phi_{T M A^{+}}^{w \rightarrow{ }^{+}}\right.$in Figure 4c-d). This highlights how small variations in the molecules can impact significantly on their physico-chemical properties and, consequently, on their transfer behaviour at liquid-liquid interfaces. From an analytical perspective, ion transfer at the ITIES provides the opportunity to measure selectively multiple ions in solution based on their intrinsic thermodynamic properties $\left(\Delta G_{t r,}^{\circ, \mathrm{w} \rightarrow \mathrm{o}}\right)$, as illustrated in Figure 4.

Typically, common pulse voltammetric techniques such as SWV, ${ }^{[54]}$ DPV $^{[55]}$ and DPSV ${ }^{[51 b, 56]}$ have been implemented to improve the sensitivity of ion detection at liquid-liquid interfaces, as these allow the effect of the charging current to be minimised, as shown in Figure $4 \mathrm{~d}$ for the transfer of tetraalkylammonium cations. As the faradaic current (IT current) decays at a slower rate than the background charging current, the current measured at the end of the pulse consists primarily of the faradaic process and discriminates against the capacitive current. Furthermore, the miniaturisation of the polarisable interfaces is a recurrent topic as multiple materials and fabrication methods have 
permitted the production of micro- and nano- pipettes and arrays. Smaller interfaces increase the current density and decrease the resistance of the cell which enhances the signal-to-noise ratio. However, this has been addressed mainly for organic compounds such as drugs. ${ }^{[33 b, 42]}$

Recently, Dryfe et al. ${ }^{[57]}$ examined the effect of a bipolar ITIES in a supported liquid membrane (SLM) on the electrochemistry of a series of ions of varied lipophilicity. The SLM consisted of a polyvinylidene fluoride (PVDF) membrane supporting the organic electrolyte phase in various organic solvents (deca-1,9-diene, 1,2-dichlorobenzene and NPOE). Although some groups ${ }^{[58]}$ around the world had already addressed the behaviour of membranes with two polarisable interfaces, the main trend with SLMs has been the investigation of only a single polarisable interface. In this work, ${ }^{[57]}$ the transfer of analytes across the membrane was followed with a photosensitive probe (rhodamine) via UV-vis absorbance, so as to determine the ion distribution profiles in the SLMs. It also showed that both the membrane and aqueous phases can behave as donor/acceptor phases due to the reversibility of the system. As a result, this behaviour could be applied to ionised drug extraction and purification, although its sensitivity was not assessed. Additionally, a supported liquid membrane, this time PVC-NPOE in a $0.45 \mu \mathrm{m}$ pore size PVDF membrane, was employed in an amperometric flowinjection system. ${ }^{[59]}$ Only one interface was polarised and it was possible to detect nanomolar concentrations of $\mathrm{TEA}^{+}$(detection limit of $5 \mathrm{nM}$ ). This flow-cell design brings a significant improvement (1-3 orders of magnitude) compared to designs prior to 2011.

A critical drawback of the IT strategy is that hydrophilic ion transfer cannot be examined, as the ion's Gibbs energy of transfer overlaps with or exceeds that of the background electrolyte ions, which limits the exploitation of the ITIES as an ion detector for many inorganic ions. To overcome this problem, Chen et al. ${ }^{[60]}$ integrated the ITIES with an anion exchange membrane (AEM) at the W/DCE interface and have found that this provided an unexpected enlargement of the potential window. This also allowed the selective separation of various anions as they presented distinguishable transfer potentials as a consequence of their interaction with the quaternary ammonium groups present in the ion channels of the AEM. ${ }^{[60]}$ Remarkably, the transfer potentials of sulfate, nitrate, perchlorate and chloride anions from water to DCE, via the AEM, were easily distinguishable. Furthermore, sulfate transfer was easier than chloride. This behaviour was attributed to the AEM performing a "predehydration" of the anions, effectively stripping the water from the anions within the pores of the membrane so that transfer into the organic phase was easier. Such behaviour has attractions for applications in sensors and chemical separation processes. 
Additionally, new forms of interfacial modification have been suggested, such as the interfaces consisting of a hybrid mesoporous silica membrane (HMSM) deposited at the ITIES. Employing a preconcentration step (90 s) for folic acid at such silica-ionic surfactant nanochannels allowed the detection of $80 \mathrm{nM}$ folic acid via DPSV. ${ }^{[56]}$ This improvement was attributed to the presence of cetyltrimethylammonium bromide (CTAB, ionic surfactant) in the pores. It was suggested that folate was extracted into the silica-CTAB ${ }^{+}$before interfacial ion transfer and was even partially dehydrated in a similar manner to what was reported for inorganic anion transfer with an AEM at the W/DCE interface. Electro-deposited silica films at the ITIES are also of increasing interest and open up new ways to modify this electrochemical interface. ${ }^{[61]}$

\section{Facilitated ion-transfer (FIT) reactions}

Another strategy to transfer, and hence detect, hydrophilic species is the addition of neutral ligands to the organic phase in order to assist their transfer. This is referred to as assisted or facilitated ion transfer (FIT) and was introduced by Koryta in 1979. ${ }^{[62]}$ FIT reactions require the presence of a complexing agent, also called a ligand or ionophore, in the organic phase. The purpose of this reagent is to lower the Gibbs energy of transfer of the ions between the phases by decreasing their solvation energy in the organic phase. This facilitates the transfer of hydrophilic ions, which in the absence of the ligand would not be detectable at the ITIES because their transfer energy overlaps with, or exceeds, that of the background electrolytes.

In this case, the mass transport process is more complex than simple IT as the transport of both ligand and target ions must be considered. Four types of ion-ligand reactions at the ITIES can be distinguished based on interfacial complexation: ${ }^{[2 a]}$

i) Transfer by interfacial complexation (TIC)

ii) Transfer by interfacial decomplexation (TID)

iii) Aqueous complexation followed by transfer (ACT)

iv) Transfer followed by organic phase complexation (TOC)

However, the complexation process can involve several steps due to a diverse ion-to-ligand reaction stoichiometry. Girault et al. ${ }^{[63]}$ proposed general thermodynamic equations for $1: m$ ion-to-ligand stoichiometries for the four listed FIT mechanisms, following from Matsuda's model ${ }^{[64]}$ of half-wave potential values for FIT reactions. These expressions are established for two limiting cases: $(i)$ an 
excess of the ligand in the organic phase relative to the ion of interest in the aqueous phase (cLinit $>>$ $\left.\mathrm{C}_{\text {Minit }}\right)$ and (ii) an excess of the ion in the aqueous phase relative to the ligand in the organic phase $\left(c_{\text {Minit }} \gg c_{L \text { Linit }}\right)$. Both regimes are based on the assumption that the complexation/decomplexation reaction is much faster than diffusion, so that the association/dissociation process is always at equilibrium. It is also assumed that diffusion of all the species are equal in both phases and that ionpairing effects or adsorption are neglected. ${ }^{[63 \mathrm{~b}]}$

Most of the FIT reactions reported at the ITIES follow TIC, TOC and TID mechanisms, whilst aqueous complexation prior to transfer (ACT) has been minimally addressed, as generally the ionophores targeted for electrochemistry at liquid-liquid interfaces are not very water-soluble. Thus, for the simplest cases of TIC, TOC or TID mechanisms for a 1:1 ion-to-ligand stoichiometry when a neutral ligand $(L)$ is present in the organic phase, the Galvani potential difference is expressed by Equation 5 .

$$
\Delta_{o}^{w} \phi=\Delta_{o}^{w} \phi_{M L}^{o}+\frac{R T}{z F} \ln \left(\frac{a_{M L}^{o}}{a_{M}^{w}}\right)
$$

where $\Delta_{0}^{\mathrm{w}} \phi$ is the measured equilibrium transfer potential difference between the two immiscible phases, $\Delta_{\mathrm{O}}^{w} \phi_{M L}^{\circ}$ is the standard transfer potential of the ion-ligand complex $\mathrm{ML}, z$ is its charge, $R$ is the universal gas constant, $T$ the temperature, $F$ the Faraday constant, $a_{M L}^{o}$ is the activity of complex $M L$ in the organic phase and $a_{M}^{w}$ is the activity of the ion $M$ in the aqueous phase. Then, the association constant $\left(K_{a}^{o}\right)$ of the complexation reaction, defined as,

$$
\mathrm{M}^{\mathrm{z}}+\mathrm{L} \rightleftarrows \mathrm{ML}^{\mathrm{z}}, \quad K_{a}^{o}=\frac{a_{M L}^{o}}{a_{M}^{o} a_{L}^{o}}
$$

in which $a_{M L}^{o}, a_{M}^{o}$ and $a_{L}^{o}$ are the activities of the ion-ligand complex, the ion and the ligand in the organic phase (o). $K_{a}^{o}$ can be determined experimentally by studying the dependence of the halfwave potential on the ion concentration in the aqueous phase when the ion concentration is in excess over that of the ligand, according to Equation 7,

$$
\Delta_{o}^{w} \phi^{1 / 2}=\Delta_{o}^{w} \phi_{M}^{o^{\prime}}+\frac{R T}{z F} \ln \left(c_{M}^{w} K_{a}^{o}\right)
$$

Numerous efforts have been made to understand ion complexation reactions at the ITIES via voltammetric analysis. ${ }^{[65]}$ Since the voltammetry of FIT reactions has become better understood, more progress in the development and application of ion sensors has been made as well as providing better understanding of methodologies such as solvent extraction processes for metal species. A 
variety of ions have been successfully studied at the ITIES via FIT reactions (e.g. alkali metals, transition metals, inorganic anions, and ionised organic compounds).

The first reported FIT process observed at the ITIES employed the crown ether ligand dibenzo-18crown-6 (DB18C6, Scheme 2), ${ }^{[62]}$ which can associate with alkali metal cations and ammonium cations. Subsequently, multiple alkali metal cation $\left(\mathrm{Li}^{+}, \mathrm{K}^{+}, \mathrm{Na}^{+}, \mathrm{Rb}^{+}, \mathrm{Cs}^{+}\right)$complexation reactions with organic phase ligands such as DB18C6 ${ }^{[66]}$ and dibenzo-15-crown-5 (DB15C5) derivatives have been studied. ${ }^{[66 a, 67]}$ These investigations focused mainly on mechanistic evaluation of the process, which provided information about the association constant and the stoichiometry of the ion-ionophore complexes. The effect of DB18C6 binding to organic compounds that possess protonated amine functional groups, via $\mathrm{H}$-bonds between the crown oxygen atoms and the protonated organic amine groups, has also been exploited as a selective label-free biosensing platform for a range of organic molecules including neurotransmitters, ${ }^{[68]}$ amino acids ${ }^{[69]}$ and oligopeptides, ${ }^{[32]}$ as discussed in the following section.

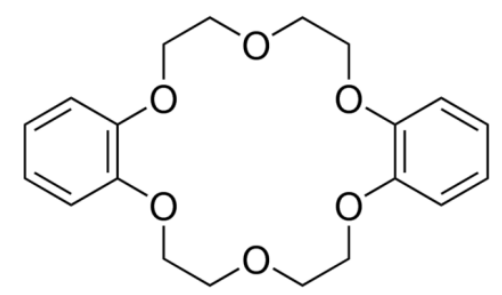

Scheme 2. DB18C6 chemical structure.

Although crown-ether ionophores have been widely investigated for alkali metal ions, alternative complexing agents based on calixarene structures for binding to e.g. $\mathrm{Na}^{+}$and $\mathrm{K}^{+}$in a $1: 1$ stoichiometry have been explored and enabled an amperometric response $(50-500 \mu \mathrm{M})$ to these cations. ${ }^{[26 b, 70]}$ The performance of other commercially available ionophores for $\mathrm{K}^{+}$and $\mathrm{Na}^{+}$such as valinomycin and bis[(12-crown-4)methyl] dodecylmethylmalonate were investigated by Bond's group. ${ }^{[71]}$ In this case, voltammetric analysis was carried out with glassy carbon electrodes modified with a drop-cast PVCTHF solution in order to form a $1 \mu \mathrm{m}$ thick ion-selective membrane. This membrane contains an ionophore, an electroactive species, a plasticizer (i.e. organic solvent, NPOE) and supporting electrolyte (such as tetraheptylammonium tetraphenylborate). Ion-exchange reactions to the 
polymeric film were probed by cyclic voltammetry to detect the potential shift upon formation of ion-ionophore interactions. Dynamic methods at membrane-based ITIES devices have been developed by Bakker's group. ${ }^{[72]}$ For example ion-selective membranes combined with liquid membranes (ionophore + plasticizer + organic electrolyte) were implemented for $\mathrm{Ca}^{2+}, \mathrm{Cl}^{-}$and protamine detection in blood samples. ${ }^{[73]}$ Also the deposition of thin (300 nm) plasticized ionselective PVC membranes on poly-3-octylthiophene (POT) modified electrodes for detection of $\mathrm{Li}^{+}$ and $\mathrm{Ca}^{2+}$ was achieved. ${ }^{[46 a]}$

As an alternative to specific ionophores, a recent report has shown that the addition of solvents such as propylenecarbonate (PC), diethylcarbonate (DEC) or dimethylcarbonate (DMC) to a DCE phase induces the assisted transfer of $\mathrm{Li}^{+}$from the aqueous phase. A mixed solvent layer is formed at the interface promoting the initial solvation of the lithium ions in the aqueous phase followed by its transfer via ACT. In this case, the additional solvent serves as the ligand to drive the FIT process, and opens up prospects for study via the ITIES of processes in Li-based batteries. ${ }^{[74]}$

Trace analysis has also been implemented for several transition metal ions. A gel-supported ITIES employing 5mM 3-(2-pyridyl)-5,6-diphenyl-1,2,4-triazine (PDT) in NPOE achieved an estimated LOD of $50 \mathrm{nM}$ for $\mathrm{Zn}^{2+}{ }^{[75]}$ determination by SWV. Also, selective detection of $\mathrm{Cu}^{2+}{ }^{[76]}$ in the presence of other ions (e.g. $\mathrm{Ni}^{2+}, \mathrm{Ba}^{2+}, \mathrm{Ca}^{2+}$ ) was possible by incorporating picolinamide-phenylenevinylene (picolamide-PV) into the organic phase and implementing DPSV with a $60 \mathrm{~s}$ preconcentration step, which produced a detection limit of $1 \mu \mathrm{M}$ (see Figure 6). As well as sensor development, the complexation process was characterised by determination of the complexation constant and stoichiometry $\left(1: 4 \mathrm{Cu}^{2+}: \mathrm{L}\right)$. Transfer of heavy metal ions by interfacial complexation with thiosemicarbazone was reported for $\mathrm{Cd}^{2+}$ and $\mathrm{Pb}^{2+} \cdot{ }^{[30 \mathrm{c}, 77]}$ Facilitated transfer of $\mathrm{Cd}^{2+}$ in a gelsupported micro-ITIES array sensor strip was reported by Lee at al., who used N,N,N',N'-Tetrabutyl3,6-dioxaoctanedi(thioamide) (ETH 1062) as the ionophore to detect $\mathrm{Cd}^{2+}$ at concentrations down to $0.2 \mu \mathrm{M}$ in as little as $20 \mu \mathrm{l}$ of sample volume. 

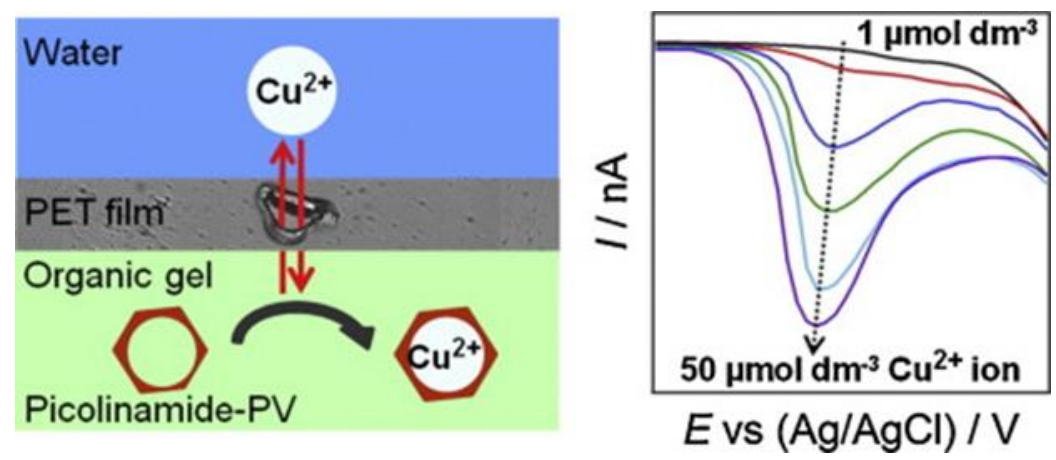

Figure 6. Differential pulse stripping voltammograms (DPSV) for the sensing of $\mathrm{Cu}$ (II) cations using a single microhole-water/PVC-1,6-DCH gel interface. The solid line is for $10 \mathrm{mM} \mathrm{LiCl}$ in the absence of $\mathrm{Cu}$ (II) cations. A $20 \mathrm{~s}$ of preconcentration by means of holding the potential of $800 \mathrm{mV}$ was used to accumulate $\mathrm{Cu}(\mathrm{II})$ cations in the gel layer before the stripping. Potential increment $=10 \mathrm{mV}$, pulse duration $=50 \mathrm{~ms}$ and pulse potential $=50 \mathrm{mV}$. Reproduced with permission from Electrochim. Acta, 123 (2014) 198, ${ }^{[76]}$ Copyright 2014 Elsevier.

As well as detection of inorganic species by FIT reactions, these processes can be linked with enzymatic activity to enable detection of organic compounds, even electrically neutral compounds. For example, glucose oxidase (GOx) reactions were followed electrochemically at the ITIES based on FIT of protons via protonation of PDT at water-gel (PVC-NPOE) interfaces. This sensor detects the protons generated enzymatically when GOx catalyses the oxidation of glucose by oxygen. Therefore, this FIT amperometric method responds indirectly to the concentrations of glucose. ${ }^{[78]}$ It exhibited a linear response between 0.2 and $3 \mathrm{mM}$ of glucose. Another commercially available ionophore for protons is octadecyl isonicotinatena (ETH1778), which was demonstrated to work in a similar range to PDT. In this case, the sensor employed DPSV to determine glucose levels in the range of blood plasma concentrations (2 - $24 \mathrm{mM}$ ) employing the same enzymatic mechanism. ${ }^{[27]}$ Another application of ETH1778 has been recently reported for a PDMS-supported sensor to detect organophosphate neurotoxins. In this case, the enzymatic reaction involves the hydrolysis of paraoxon (concentration range of 0.5 to $100 \mu \mathrm{M}$ ) by organophosphorus hydrolase (OPH), producing phosphoric acid and $p$-nitrophenol and the consequent release of protons, which are detected by FIT at the sensor interface. ${ }^{[79]}$

In contrast to the large variety of studies on FIT of cations, there have been fewer papers published on FIT of inorganic anions at the ITIES. The assisted transfer of phosphate at water/DCE interfaces employing a bis-urea-calix[4]aren $e^{[80]}$ as receptor was reported, together with a similar study at 
water/NB interfaces with a bis-thiourea ligand. ${ }^{[81]}$ Shao et al. ${ }^{[82]}$ reported the facilitated ion transfer of four anions $\left(\mathrm{NO}_{2}{ }^{-}, \mathrm{Cl}^{-}, \mathrm{Br}^{-}\right.$and $\left.\mathrm{COO}^{-}\right)$facilitated by calix-pyrrole ligands at a micro-interface, while Dryfe and colleagues ${ }^{[83]}$ reported the transfers of a series of anions facilitated by a cholapod ionophore, and determined their complexation constants.

Fewer ionophores are available for anion complexation, and discovery of new ionophores remains a strong activity within inorganic and supramolecular research areas. Anions are larger than cations, often sensitive to $\mathrm{pH}$, vary in geometry and can interact with solvents, which make them challenging analytes to study at the liquid-liquid interfaces. ${ }^{[84]}$ This explains the limited number of electrochemical studies of anionic species at the ITIES. Nonetheless, with the advantages of ionophore-based ion recognition used in ion-selective-electrodes (ISE), ${ }^{[73,85]}$ a wide range of ionophores have become available and could potentially be examined and exploited at the ITIES. A review by Beer and Gale listed 156 receptors for anion recognition up to $2001 .{ }^{[84]}$ In addition, Buhlmann et al. provided an extensive list of receptors for cationic and anionic potentiometric sensors $^{[86]}$ which can be a useful guide to tailor specific receptors for target analytes.

Thus, it is clear that better ion receptors (ligands/ionophores) in combination with strategies such as ion exchange membranes, supported liquid membranes and flow systems could potentially result in improved devices for ion detectors. The impact of selective membranes seems to modify the hydration shell of the ions from the aqueous phase which have an enormous implication in selective analysis. Therefore, the addition of a chemically modified porous thin layer/ion-channel membranes can potentially be a simple solution for an ongoing issue in electrochemical sensing. ${ }^{[87]}$

\section{Detection of bioactive small organic molecules}

Over recent years, the electrochemistry at ITIES has been applied to investigation of many small organic ions of biomedical importance. Both synthetic drug substances and natural biochemicals, such as neurotransmitters, have been subjected to studies at the ITIES. Yudi et al. ${ }^{[19 a, 19 b, 88]}$ studied the interaction of drug substances with liposomes at liquid-liquid interfaces by combination of electrochemical techniques and other analytical approaches. They studied the interaction of triflupromazine (TPF) with distearoylphosphatidylglycerol (DSPG) films at the water-DCE interface by CV, which was further confirmed by surface pressure isotherms. ${ }^{[19 a]}$ It was found that TPF partitioned 
into the DSPG monolayer and changed the structure of the interfacial film; a fluidizing effect was evident, dependent on the interaction time and drug concentration, which lead to an increase in the permeability of the film. They also examined the effect of flunitrazepam (FNTZ) on molecular packing of distearoylphosphatidic acid (DSPA) adsorbed at the air-water and the water-DCE interfaces. ${ }^{[19 b]}$ The results indicated that FNTZ incorporation into the DSPA monolayer changed the state of the film, so that a decrease in the permeability of the film was observed due to a structuring effect, which depended on the $\mathrm{pH}$ and the cation present in the aqueous electrolyte. Furthermore, quantitative analysis of boldine alkaloid in natural extracts was performed at liquid-liquid interfaces using CV. ${ }^{[88]}$ The calibration curves in the concentration range of $1.04 \times 10^{-5} \mathrm{M}$ to $5.19 \times 10^{-4} \mathrm{M}$ were obtained with a detection limit of $(6.1 \pm 0.7) \times 10^{-5} \mathrm{M}$. The results for voltammetric detection of boldine alkaloid in boldo leaf extracts were in agreement with those obtained by a liquid chromatography method, and hence provided a basis for application of the electrochemistry at the ITIES to drug analysis in a complex matrix.

Ionisable drug molecules, neurotransmitters and related substances ${ }^{[25 c, 89]}$ continue to be of interest for detection by electrochemistry at the ITIES of various dimensions. Velicky et al. ${ }^{[19 c]}$ proposed a novel method to study the transfer of two partially ionised drug molecules, warfarin and propranolol, across a liquid-liquid interface by employing a lipophilic membrane in a rotating system. This approach used controlled hydrodynamics to eliminate unfavourable partitioning effects at the interface, thus enabling physically reasonable values of the aqueous diffusion coefficients to be determined for the drug molecules. Propranolol continues to be a model drug substance for demonstrating the detection possibilities of various ITIES platforms, following work by Cunnane and others. $\left.{ }^{[2,}, 90\right]$ Vazquez et al. ${ }^{[33 a]}$ described a microneedle array platform with an embedded microITIES array for the electrochemical detection of propranolol. The suggestion here is that the microneedles provide a direct access to biological fluids by piercing the skin, and these biological fluids form the ITIES when in contact with gelled organic phase held within the needles. Although testing in through-skin applications was not reported, the analytical performances of this novel platform were evaluated via differential pulse stripping voltammetry (DPSV), indicating a sensitivity of $43 \mathrm{nA} \mu \mathrm{M}^{-1}$, a detection limit of $50 \mathrm{nM}$ and a linear range between 50 and $200 \mathrm{nM}$, which encompassed the values of pharmacological relevance. The transfer potential of propranolol is within the range easily available at W/DCE and W/DCH interfaces, which explains its wide interest as a demonstrator compound for drug analyses at the ITIES. For example, Lopes and Kataky ${ }^{[91]}$ reported 
the use of electrochemistry at a micro-ITIES to study chiral interactions of propranolol enantiomers with the protein alpha1-acid-glycoprotein. In this case, the drug enantiomers bind to the protein in the aqueous phase and only unbound drug is detected by ion-transfer voltammetry. Scratchard analysis was used to compare the binding of enantiomers to the protein. The ion-transfer voltammetric detection of propranolol was also explored at arrays of nano-ITIES formed at silicon nitride nanoporous membranes with 400 pores in a hexagonal arrangement, with either 50 or $17 \mathrm{~nm}$ radius pores. ${ }^{[22]}$ Both arrays achieved the equivalent detection limit of $0.8 \mu \mathrm{M}$ using $\mathrm{CV}$, and the smaller nano-ITIES exhibited higher sensitivity toward propranolol transfer than the larger one, which can be attributed to the enhanced ion flux resulting from the convergent diffusion at smaller electrochemical interfaces (Figure 7). However, diffusion zone overlap occurred at the nanolTIES in this array, leading to depletion zones between neighbouring nanointerfaces, and which was illustrated by finite element simulation of an interface in the midst of the array. Thus, improved analytical performances may be achieved by increasing the distances between adjacent nanopores in the array used to pattern the nanoITIES.
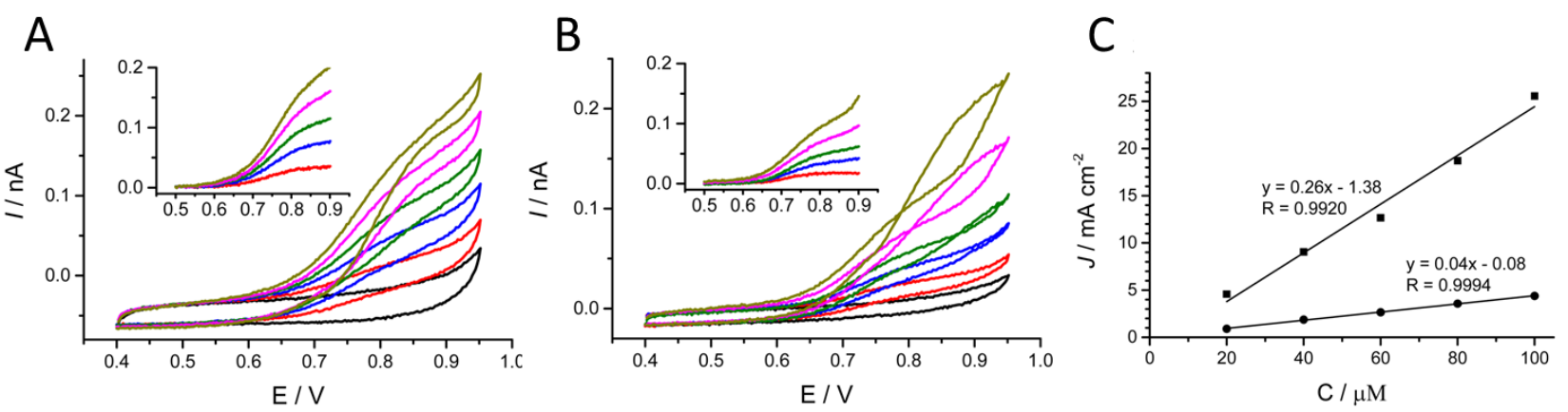

Figure 7. $\mathrm{CVs}$ of 0 (black), $20 \mu \mathrm{M}$ (red), $40 \mu \mathrm{M}$ (blue), $60 \mu \mathrm{M}$ (green), $80 \mu \mathrm{M}$ (pink), and $100 \mu \mathrm{M}$ (orange) protonated propranolol transfer across 50 (A) and $17 \mathrm{~nm}(\mathrm{~B})$ radius nanoITIES arrays. The insets show the corresponding background-subtracted voltammograms. (C) Calibration plots of current density versus propranolol concentration $(20-100 \mu \mathrm{M})$ obtained at 50 (circles) and $17 \mathrm{~nm}$ (squares) radius nanoITIES, sweep rate: $5 \mathrm{mV} \mathrm{s}^{-1}$. Reproduced with permission from Anal. Chem. 2015, 87, 4487. ${ }^{[42]}$ Copyright 2015 American Chemical Society.

Recently, Sairi and Arrigan ${ }^{[33 b]}$ demonstrated the electrochemical detection of ractopamine at arrays of micro-ITIES by CV and linear sweep stripping voltammetry (LSSV). The thermodynamic parameters 
of the drug were investigated, such as the formal transfer potential and the Gibbs transfer energy. A limit of detection of $0.1 \mu \mathrm{M}$ was achieved under the optimised detection conditions, despite the fact that the drug transferred at the limit of the available potential window. A study of possible interferences indicated that potassium ions and serum protein interfered in the detection signal, and indicated that sample pretreatment is required for bioanalytical applications to be feasible. The detection of the water-soluble anti-cancer drug Topotecan (topotecan hydrochloride hydrate) by stripping voltammetry at a microhole-supported water/organogel interface was reported by Kim et al., ${ }^{[92]}$ achieving concentration detection limits of $0.1 \mu \mathrm{M}$, while Ribeiro et al. ${ }^{\left[{ }^{[3]}\right.}$ studied the wellknown anti-cancer drug daunorubicin and determined its thermodynamic properties as well as establishing detection at concentrations down to $0.8 \mu \mathrm{M}$

The detection of neurotransmitters such as dopamine ${ }^{[68 a, 68 b, 94]}$ is well-established at the ITIES, and studies towards improving the detection of this and related protonated amines has continued. Ribeiro et al. ${ }^{[68 c, 95]}$ and Torralba et al. ${ }^{[96]}$ have reported the facilitated ion transfer of catecholamine and organic amines (heptylamine, octylamine, decylamine, procaine and procainamide) by DB18C6, using cyclic and square wave voltammetry. Regarding the determination of dopamine and noradrenaline, the detection limits of 0.35 and $1.7 \mu \mathrm{M}$ were achieved, respectively, and the selectivity coefficient obtained in the presence of ascorbic acid were $3.5 \times 10^{-4}$ for dopamine and 2.5 $\times 10^{-3}$ for noradrenaline. Dopamine and daunomycin interaction at the ITIES with DNA was also reported by Ribeiro et al. ${ }^{[93 b]}$ The detection at nanomolar levels of the drugs fluoxetine, citalopram and sertraline in drinking and river water was reported by Izadyar et al.., ${ }^{[97]}$ who employed a thin-film approach on a pencil lead electrodes for detection purposes. Tatsumi et al. ${ }^{[20]}$ investigated the transfer of cationic forms of tryptamine and serotonin across the water-NB interface by CV, and welldefined voltammetric waves were observed within the available potential window. The cationic form of tryptophan transferring across NB-water interface was also studied using an acidic aqueous solution. Colombo et al. ${ }^{[98]}$ reported the detection of acetylcholine, serotonin and tryptamine on the nano-ITIES formed at nanopipettes with sizes ranging from a radius of ca. $7 \mathrm{~nm}$ to $35 \mathrm{~nm}$, using CV and amperometry. The detection was linear in the range of $0.25-6 \mathrm{mM}$ for acetylcholine and of 0.5 - $10 \mathrm{mM}$ for tryptamine in artificial sea water. Transfer of serotonin was linear in the range of 0.15 $8 \mathrm{mM}$ in $\mathrm{LiCl}$ solution. The detection limit for serotonin on a radius ca. $21 \mathrm{~nm}$ nanopipette, acetylcholine on a radius ca. $7 \mathrm{~nm}$ nanopipette and tryptamine on a radius ca. $19 \mathrm{~nm}$ were 77, 205 and $86 \mu \mathrm{M}$, respectively. A recent report for this group also extends the detection of dopamine to 
nanopipettes ITIES, although detection levels were within the $100 \mu \mathrm{M}$ region. ${ }^{[99]}$ These relatively high detection levels might be suitable for detection of local concentrations at points of release, e.g. from neural cells.

\section{Detection of (bio)macromolecules}

Electrochemical detection of macromolecules at polarisable liquid-liquid interfaces has attracted attention as it provides the basis for label-free sensing of such biomolecules in a non-redox manner. This label-free strategy might be of interest, for example, in applications such as biosensors and point-of-care testing. ${ }^{[25 c, 100]}$ The first investigations of proteins at the ITIES dates from the 1980s, when Vanysek and colleagues ${ }^{[101]}$ reported the interfacial adsorption of ovalbumin, which was shown to alter a simple IT process. Subsequently, there were few studies of proteins undertaken, in comparison to studies of small molecules. ${ }^{[8]}$

A small selection of peptides and proteins ${ }^{[4]}$ has been characterised electrochemically at the ITIES considering that the estimated number of proteins in human cells is between 250,000 to one million. This selection includes $d i$ - and tri-peptides, ${ }^{[32]}$ melittin, ${ }^{[102]}$ amylin, ${ }^{[103]}$ protamine, ${ }^{[104]}$ insulin, ${ }^{[105]}$ myoglobin, ${ }^{[106]}$ cytochrome $c^{[107]}$ lysozyme, ${ }^{[21 a, 108]}$ hemoglobin ${ }^{[109]}$ and albumin, ${ }^{[21 d, 105 c, 110]}$ which are listed here in order of increasing molecular mass ( $<1$ to ca. $66 \mathrm{kDa}$ ). The key results from mechanistic studies of proteins at the ITIES have shown that detection is possible when the $\mathrm{pH}$ of the aqueous phase was below the isoelectric point (pl) of the protein. ${ }^{[105 a, 108 a, 109 a]}$ Thus, the ionisable groups in the amino acid sequence (amine side chain groups, i.e. lysine and arginine) of the protein were positively charged. Once the protein is fully protonated, it can undergo diverse IT or FIT reactions depending on its size, structure, hydrophobicity and number of charges. Dependent on protein size and structure, complexation of the organic phase anion is suggested to be the basis of protein detection, with formation of the complex between anion and the cationic protein occurring on the aqueous side of the interface. Smaller polypeptides behave differently. For instance, the polypeptide rat amylin was detected via cyclic voltammetry under physiological conditions, ${ }^{[103]}$ due to its high $\mathrm{pl}$ which can be advantageous if interferences can be discriminated by tuning the $\mathrm{pH}$ and it exhibited voltammograms consistent with its transfer across the ITIES. 
In 2008, di- and tri-peptides of lysine, leucine and phenylanaline were investigated at micro-array interfaces by FIT reactions based on complexation with DB18C6, ${ }^{[32]}$ following on from the work by Shao ${ }^{[69]}$ and Osakai ${ }^{[111]}$ groups. Submicromolar detection (ca. $\left.0.4 \mu \mathrm{M}\right)$ was reported by a combination of micro-interfaces and stripping voltammetry. Furthermore, different generations (sizes) of poly-Llysine dendrigrafts showed similar behaviour at liquid-liquid interfaces as large proteins, because the size and charge of the dendrigrafts increases with generation number. ${ }^{[112]}$ Hence, this study was able to address the effect of controlled size and charge on the electrochemical response, confirming that both factors impact on the analytical sensitivity. In fact, the lysine dendrigraft electrochemical data were compared to previous data on insulin, lysozyme and haemoglobin behaviour, all of which can change their tertiary structures at the interface to favour interactions with the organic electrolytes. However, submicromolar concentrations were still detected by simply implementing cyclic voltammetry. ${ }^{[112]}$

More recently, a range of polypeptides and proteins were examined for detection by interfacial complexation at water-organic interfaces modified with surfactants. Protamine, a highly charge polypeptide, has been extensively studied since Amemiya et al. reported its activity at liquid-liquid interfaces. ${ }^{[104 a]}$ The effect of anionic surfactants (i.e. dinonylnaphthalenesulfonate, DNNS') as a ligand that assists the transfer of this polypeptide pointed to a one-to-one charge stoichiometry balance between the peptide and surfactant (protamine ${ }^{20+}-20$ DNNS$\left.^{-}\right) .^{[104 b]}$ Other reports where anionic surfactants such as 1,4-bis(2-ethylhexoxy)-1,4-dioxobutane-2-sulfonate (AOT') were added to the organic phase demonstrated the reverse-micelle electroextraction of cytochrome $c$ into a DCE organic phase. ${ }^{[113]}$ Osakai and colleagues investigated three different surfactants to show a selective transfer-adsorption process of the protein by simply modifying the organic phase with the surfactant, where it functions as a protein receptor. In 2012, a flow system implementing protein-DNNS interactions for albumin detection in artificial urine achieved a LOD of $1.2 \mu \mathrm{M}$. ${ }^{[21 d]}$ Subsequently, $\mathrm{O}^{\prime}$ Sullivan and Arrigan ${ }^{[107 c]}$ showed that w/PVC-DCH interfaces modified with AOT' $^{-}$showed an increase of the faradaic current (6-fold) and interfacial coverage (17-fold) for the detection of myoglobin which confirmed the ability of protein-surfactant complexes to enhance the electrochemical signal. On the other hand, cationic surfactants were reported to bind DNA ${ }^{[22,114]}$ although little additional work has been carried out in this direction. 
Additionally, other polyions such as heparin, a negatively charge glycosaminoglycan that can interact with antithrombin III and which is used clinically as an anticoagulant, have been shown to be electrochemically active at the ITIES. ${ }^{[115]}$ Langmaier et al. ${ }^{[116]}$ developed the amperometric extraction of heparin via tridodecylmethylammonium cation-heparin interactions, which again resembles the protein-surfactant extraction methodology discussed previously.

In parallel to these studies, protein adsorption processes observed by several groups were evaluated from an analytical point of view. A report in $2012^{[108 b]}$ showed that multilayer adsorption can be advantageously employed for quantitative analysis as it could be controlled by the adsorption potential and the adsorption time. This process consists of pre-concentrating the protein at the microITIES via application of the adsorption potential for a period of time. This is followed by an electrochemical desorption of the protein. This strategy, referred to as adsorptive stripping voltammetry (AdSV), has been implemented for hen-egg-white-lysozyme, ${ }^{[108 b]}$ haemoglobin ${ }^{[109 c]}$ and insulin ${ }^{[105 c]}$ in the presence of albumin. In the latter, insulin and albumin showed different adsorption potentials, which was used as a way to selectively detect insulin in the presence of serum albumin. The limits of detection for these proteins via AdSV were reported in the nanomolar range (ca. 10, 30 and $48 \mathrm{nM}$ for insulin, lysozyme and haemoglobin). More recently, application of adsorptive differential pulse stripping voltammetry (AdDPSV) of lysozyme enabled the detection limit for this model protein to be lowered from $30 \mathrm{nM}$ to $10 \mathrm{nM} .^{[108 f]}$

Analogous methodology was performed at water-room temperature ionic liquid (water/trihexyl(tetradecyl)phosphonium tris(pentafluorethyl)trifluorphosphate, $w /\left[P_{14,6,6,6}\right][F A P]$ ) microinterfaces ${ }^{[117]}$ which generated a smaller potential window ( $\left.0.5 \mathrm{~V}\right)$ but still suggested a proteinFAP affinity at the more positive potentials applied for the electroadsorption approach. ${ }^{[108 c]}$ Nonetheless, as the transfer potential window was reduced to half the size obtained for w/DCH, the detection limit for lysozyme at this w/RTIL was $2.5 \mu \mathrm{M}$.

With specific regard to the detection mechanism for protein at the ITIES, FIT of organic phase electrolyte anions is believed to be facilitated by the cationic protein, and the product of this reaction adsorbs at the interface. Studies by biphasic electrospray ionisation - mass spectrometry ${ }^{[21 a]}$ showed that the lysozyme - anion complexes were detectable under such conditions, providing a key evidence for the suggested mechanism. The implications of such complexation and adsorption on the structure of the protein remain an open question. Recent results from electrostatic spray 
ionisation - mass spectrometry $\left(\right.$ ESTASI-MS) ${ }^{[108 \mathrm{e}]}$ of lysozyme at a water/PVC-DCH gel interface confirmed the multilayer adsorption proposed for the AdSV detection mechanism. In addition, structural changes in the protein were observed in the different layers formed at the organogel surface, depending on the applied potential, the adsorption time and the lysozyme concentration.

Finally, voltammetric analysis of denatured, ${ }^{[21 b]}$ digested $^{[118]}$ and unfolded ${ }^{[21 c]}$ haemoglobin by Herzog and colleagues opened up a new avenue for proteomic investigations at the ITIES, although this has not been reported any further as these reactions actually decrease the protein signal intensity and therefore reducing its analytical abilities.

\section{Conclusions}

Electrochemistry at interfaces formed between immiscible electrolyte solutions can be used to detect a range of ions by non-redox ion transfer processes. While the physical basis of the electrochemistry is well established, new electroanalytical directions have emerged in recent years, including microand nano-interfaces, biomolecular adsorption/stripping and its combination with other techniques such as mass spectrometry and spectroscopy methods. This review has sought to provide an introduction to the topic and to highlight a number of recent advances. Key challenges into the future include elucidation of the response behaviour of nanoscale interfaces in array format and the understanding of molecular changes in large biomolecules as they interact with the interface. It is clear that a larger number of biomolecules should be investigated systematically in an attempt to comprehend the mechanism driving the adsorption of macromolecules at the ITIES. Subsequently, this would allow the prediction of their electrochemical behaviour or even the incorporation of receptor-like electrolytes or ligands (either neutral ionophores or surfactants) in the organic solution based on the optimum macromolecule-receptor affinity. And it would address the main concern encountered at the ITIES, the selectivity. Similarly to IT and FIT, the integration of modifiedmembranes at the interface, could potentially help the selective detection of various macromolecules as their different affinity to the immobilized charged groups within the channels could result in distinguishable transport rates.

\section{Acknowledgements}


Support from Curtin University and the Australian Research Council (DP130102040) is gratefully acknowledged.

\section{References}

[1] Z. Samec. Electrochemistry at the interface between two immiscible electrolyte solutions. Pure and Applied Chemistry. 2004, 76, 2147.

[2] (a) P. Peljo, H. H. Girault. in Encyclopedia of Analytical Chemistry 2006, (John Wiley \& Sons, Ltd); (b) G. Herzog. Recent developments in electrochemistry at the interface between two immiscible electrolyte solutions for ion sensing. Analyst. 2015, 140, 3888.

[3] Z. Samec, E. Samcova, H. H. Girault. Ion amperometry at the interface between two immiscible electrolyte solutions in view of realizing the amperometric ion-selective electrode. Talanta. 2004, 63, 21.

[4] D. W. M. Arrigan. Voltammetry of proteins at liquid-liquid interfaces. Annual Reports on the Progress of Chemistry 2013, Vol 109, Section C: Physical Chemistry. 2013, 109, 167.

[5] (a) Z. Samec. Dynamic electrochemistry at the interface between two immiscible electrolytes. Electrochimica Acta. 2012, 84, 21; (b) R. A. W. Dryfe. in Advances in Chemical Physics, Vol 141 (Ed. Rice SA) 2009, pp. 153-215.

[6] I. Benjamin. Mechanism and dynamics of ion transfer across a liquid-liquid interface. Science. 1993, $261,1558$.

[7] H. H. Girault. in Electroanalytical Chemistry, A Series of Advances, Vol 23 Eds. Bard AJ, Zoski CG) 2010, pp. 1-104 (Dekker: New York).

[8] (a) S. J. Liu, Q. Li, Y. H. Shao. Electrochemistry at micro- and nanoscopic liquid/liquid interfaces. Chem Soc Rev. 2011, 40, 2236; (b) Y. X. Wang, J. Velmurugan, M. V. Mirkin, P. J. Rodgers, J. Kim, S. Amemiya. Kinetic Study of Rapid Transfer of Tetraethylammonium at the 1,2-Dichloroethane/Water Interface by Nanopipet Voltammetry of Common Ions. Analytical Chemistry. 2010, 82, 77; (c) P. J. Rodgers, S. Amemiya, Y. X. Wang, M. V. Mirkin. Nanopipet Voltammetry of Common lons across the Liquid-Liquid Interface. Theory and Limitations in Kinetic Analysis of Nanoelectrode Voltammograms. Analytical Chemistry. 2010, 82, 84.

[9] P. Vanysek, L. B. Ramirez. Interface between two immiscible liquid electrolytes: A review. J Chil Chem Soc. 2008, 53, 1455.

[10] Z. Samec, V. Marecek, J. Weber. Charge transfer between two immiscible electrolyte solutions. 2. Investigation of $\mathrm{Cs}+$ ion transfer across the nitrobenzene-water interface by cyclic voltammetry with IR drop compensation Journal of Electroanalytical Chemistry. 1979, 100, 841.

[11] S. Nishizawa, T. Kamaishi, T. Yokobori, R. Kato, Y. Y. Cui, T. Shioya, et al. Facilitated sulfate transfer across the nitrobenzene-water interface as mediated by hydrogen-bonding ionophores. Analytical Sciences. 2004, 20, 1559.

[12] H. Katano, H. Tatsumi, M. Senda. Ion-transfer voltammetry at 1,6-dichlorohexane vertical bar water and 1,4-dichlorobutane vertical bar water interfaces. Talanta. 2004, 63, 185.

[13] (a) P. S. Toth, R. A. W. Dryfe. Novel organic solvents for electrochemistry at the liquid/liquid interface. Analyst. 2015, 140, 1947; (b) A. J. Olaya, P. Y. Ge, H. H. Girault. Ion transfer across the water vertical bar trifluorotoluene interface. Electrochemistry Communications. 2012, $19,101$.

[14] M. Velicky, K. Y. Tam, R. A. W. Dryfe. On the stability of the silver/silver sulfate reference electrode. Analytical Methods. 2012, 4, 1207.

[15] D. J. Clarke, D. J. Schiffrin, M. C. Wiles. A tetraphenylborate internal reference electrode for immiscible electrolyte solutions and ion-selective electrodes. Electrochimica Acta. 1989, 34, 767.

[16] G. Taylor, H. H. J. Girault. Ion transfer reactions across a liquid-liquid interface supported on a micropipette tip Journal of Electroanalytical Chemistry. 1986, 208, 179.

[17] J. A. Campbell, H. H. Girault. Steady-state current for ion transfer reactions at a micro liquid liquid interface Journal of Electroanalytical Chemistry. 1989, 266, 465. 
[18] Y. H. Shao, B. Liu, M. V. Mirkin. Studying ionic reactions by a new generation/collection technique. Journal of the American Chemical Society. 1998, 120, 12700.

[19] (a) M. V. C. Quiroga, L. M. A. Monzon, L. M. Yudi. Interaction of triflupromazine with distearoylphosphatidylglycerol films studied by surface pressure isotherms and cyclic voltammetry at a 1,2dichloroethane/water interface. Electrochimica Acta. 2010, 55, 5840; (b) M. V. C. Quiroga, L. M. A. Monzon, L. M. Yudi. Voltammetric study and surface pressure isotherms describing Flunitrazepam incorporation into a distearoylphosphatidic acid film adsorbed at air/water and water/1,2-dichloroethane interfaces.

Electrochimica Acta. 2011, 56, 7022; (c) M. Velicky, K. Y. Tam, R. A. W. Dryfe. Hydrodynamic voltammetry at the liquid-liquid interface: Application to the transfer of ionised drug molecules. Journal of Electroanalytical Chemistry. 2012, 683, 94.

[20] H. Tatsumi, T. Ueda. Ion transfer voltammetry of tryptamine, serotonin, and tryptophan at the nitrobenzene/water interface. Journal of Electroanalytical Chemistry. 2011, 655, 180.

[21] (a) R. A. Hartvig, M. A. Mendez, M. van de Weert, L. Jorgensen, J. Ostergaard, H. H. Girault, et al. Interfacial complexes between a protein and lipophilic ions at an oil-water interface. Analytical Chemistry. 2010, 82, 7699; (b) G. Herzog, P. Eichelmann-Daly, D. W. M. Arrigan. Electrochemical behaviour of denatured haemoglobin at the liquid/liquid interface. Electrochemistry Communications. 2010, 12, 335; (c) G. Herzog, M. T. Nolan, D. W. M. Arrigan. Haemoglobin unfolding studies at the liquid-liquid interface. Electrochemistry Communications. 2011, 13, 723; dR. Matsui, T. Sakaki, T. Osakai. Label-Free Amperometric Detection of Albumin with an Oil/Water-type Flow Cell for Urine Protein Analysis. Electroanalysis. 2012, 24, 1164.

[22] F. Kivlehan, M. Lefoix, H. A. Moynihan, D. Thompson, V. I. Ogurtsov, G. Herzog, et al. Interaction of acridine-calix 4 arene with DNA at the electrified liquid liquid interface. Electrochimica Acta. 2010, 55, 3348.

[23] (a) B. Su, I. Hatay, A. Trojanek, Z. Samec, T. Khoury, C. P. Gros, et al. Molecular Electrocatalysis for Oxygen Reduction by Cobalt Porphyrins Adsorbed at Liquid/Liquid Interfaces. Journal of the American Chemical Society. 2010, 132, 2655; (b) V. S. Patil, S. R. Krishna, R. R. Hawaldar, A. B. Gaikwad, S. D. Sathaye, K. R. Patil. One-step in situ synthesis of $\mathrm{NHx}$-adsorbed rhodium nanocrystals at liquid-liquid interfaces for possible electrocatalytic applications. Journal of Colloid and Interface Science. 2011, 358, 238; (C M. A. Mendez, R. Partovi-Nia, I. Hatay, B. Su, P. Y. Ge, A. Olaya, et al. Molecular electrocatalysis at soft interfaces. Physical Chemistry Chemical Physics. 2010, 12, 15163.

[24] (a) S. G. Booth, D. P. Cowcher, R. Goodacre, R. A. W. Dryfe. Electrochemical modulation of SERS at the liquid/liquid interface. Chemical Communications. 2014, 50, 4482; (b) J. B. Edel, A. A. Kornyshev, M. Urbakh. Self-Assembly of Nanoparticle Arrays for Use as Mirrors, Sensors, and Antennas. ACS Nano. 2013, 7 , 9526.

[25] (a) A. Molina, J. A. Ortuno, C. Serna, E. Torralba, J. Gonzalez. Advances in the Study of Ion Transfer at Liquid Membranes with Two Polarized Interfaces by Square Wave Voltammetry. Electroanalysis. 2010, 22, 1634; (b) H. A. Santos, V. Garcia-Morales, C. M. Pereira. Electrochemical Properties of Phospholipid Monolayers at Liquid-Liquid Interfaces. Chemphyschem. 2010, 11, 28; (c) D. W. M. Arrigan, G. Herzog, M. D. Scanlon, J. Strutwolf. in Electroanalytical Chemistry, A Series of Advances Eds. Bard AJ, Zoski CG) 2013, pp. 105-178 (CRC Press: Boca Raton).

[26] (a) T. J. Stockmann, Z. F. Ding. Facile determination of formal transfer potentials for hydrophilic alkali metal ions at water vertical bar ionic liquid microinterfaces. Physical Chemistry Chemical Physics. 2012, 14, 13949; (b) M. Durmaz, E. Zor, E. Kocabas, H. Bingol, E. G. Akgemci. Voltammetric characterization of selective potassium ion transfer across micro-water/1,2-dichloroethane interface facilitated by a novel calix 4 arene derivative. Electrochimica Acta. 2011, 56, 5316.

[27] S. N. Faisal, C. M. Pereira, S. Rho, H. J. Lee. Amperometric proton selective sensors utilizing ion transfer reactions across a microhole liquid/gel interface. Physical Chemistry Chemical Physics. 2010, 12, 15184.

[28] B. Liu, Y. H. Shao, M. V. Mirkin. Dual-pipet techniques for probing ionic reactions. Analytical Chemistry. 2000, 72, 510.

[29] (a) R. Zazpe, C. Hibert, J. O'Brien, Y. H. Lanyon, D. W. M. Arrigan. Ion-transfer voltammetry at silicon membrane-based arrays of micro-liquid-liquid interfaces. Lab on a Chip. 2007, 7, 1732; (b) G. Herzog, V. Beni. Stripping voltammetry at micro-interface arrays: A review. Analytica Chimica Acta. 2013, 769, 10. 
[30] (a) A. Mastouri, S. Peulon, N. Bellakhal, A. Chausse. M(II) transfer across a liquid-liquid microinterface facilitated by a complex formation with 8-Hydroxyquinoline: Application to quantification of $\mathrm{Pb}(\mathrm{II}), \mathrm{Cd}(\mathrm{II})$ and $\mathrm{Zn}$ (II) alone or in mixture in effluents. Electrochimica Acta. 2014, 130, 818; (b) A. Mastouri, S. Peulon, D. Farcage, N. Bellakhal, A. Chausse. Perfect additivity of microinterface arrays for liquid-liquid measurements: Application to cadmium ions quantification. Electrochimica Acta. 2014, 120, 212; (c) H. J. Lee, G. Lagger, C. M. Pereira, A. F. Silva, H. H. Girault. Amperometric tape ion sensors for cadmiurn(II) ion analysis. Talanta. 2009, 78, 66.

[31] A. Berduque, R. Zazpe, D. W. M. Arrigan. Electrochemical detection of dopamine using arrays of liquid-liquid micro-interfaces created within micromachined silicon membranes. Analytica Chimica Acta. 2008, 611, 156.

[32] M. D. Scanlon, G. Herzog, D. W. M. Arrigan. Electrochemical detection of oligopeptides at siliconfabricated micro-liquid vertical bar liquid interfaces. Analytical Chemistry. 2008, 80, 5743.

[33] (a) P. Vazquez, G. Herzog, C. O'Mahony, J. O'Brien, J. Scully, A. Blake, et al. Microscopic gel-liquid interfaces supported by hollow microneedle array for voltammetric drug detection. Sensors and Actuators BChemical. 2014, 201, 572; (b) M. Sairi, D. W. M. Arrigan. Electrochemical detection of ractopamine at arrays of micro-liquid | liquid interfaces. Talanta. 2015, 132, 205.

[34] (a) S. Amemiya, Y. Wang, M. V. Mirkin. in Specialist Periodical Reports - Electrochemistry (Ed. J.D. Wadhawan R.G. Compton) 2014, pp. 1-43 (Royal Society of Chemistry Cambridge); (b) D. W. M. Arrigan. Nanoelectrodes, nanoelectrode arrays and their applications. Analyst. 2004, 129, 1157; (c) M. D. Scanlon, D. W. M. Arrigan. Enhanced Electroanalytical Sensitivity via Interface Miniaturisation: Ion Transfer Voltammetry at an Array of Nanometre Liquid-Liquid Interfaces. Electroanalysis. 2011, 23, 1023.

[35] (a) F. O. Laforge, J. Carpino, S. A. Rotenberg, M. V. Mirkin. Electrochemical attosyringe. Proceedings of the National Academy of Sciences of the United States of America. 2007, 104, 11895; (b) M. Shen, M. L. Colombo. Electrochemical nanoprobes for the chemical detection of neurotransmitters. Analytical Methods. 2015, 7, 7095.

[36] M. D. Scanlon, J. Strutwolf, A. Blake, D. Iacopino, A. J. Quinn, D. W. M. Arrigan. Ion-Transfer Electrochemistry at Arrays of Nanointerfaces between Immiscible Electrolyte Solutions Confined within Silicon Nitride Nanopore Membranes. Analytical Chemistry. 2010, 82, 6115.

[37] (a) M. Sairi, N. Chen-Tan, G. Neusser, C. Kranz, D. W. M. Arrigan. Electrochemical Characterisation of Nanoscale Liquid|Liquid Interfaces Located at Focused Ion Beam-Milled Silicon Nitride Membranes.

ChemElectroChem. 2015, 2, 98; (b) Y. Liu, M. Sairi, G. Neusser, C. Kranz, D. W. M. Arrigan. Achievement of Diffusional Independence at Nanoscale Liquid Liquid Interfaces within Arrays. Analytical Chemistry. 2015, 87, 5486.

[38] Q. Li, S. B. Xie, Z. W. Liang, X. Meng, S. J. Liu, H. H. Girault, et al. Fast lon-Transfer Processes at Nanoscopic Liquid/Liquid Interfaces. Angew Chem-Int Edit. 2009, 48, 8010.

[39] M. Shen, R. Ishimatsu, J. Kim, S. Amemiya. Quantitative Imaging of Ion Transport through Single Nanopores by High-Resolution Scanning Electrochemical Microscopy. Journal of the American Chemical Society. 2012, 134, 9856.

[40] M. Rimboud, R. D. Hart, T. Becker, D. W. M. Arrigan. Electrochemical behaviour and voltammetric sensitivity at arrays of nanoscale interfaces between immiscible liquids. Analyst. 2011, 136, 4674.

[41] M. Sairi, J. Strutwolf, R. A. Mitchell, D. S. Silvester, D. W. M. Arrigan. Chronoamperometric response at nanoscale liquid-liquid interface arrays. Electrochimica Acta. 2013, 101, 177.

[42] Y. Liu, J. Strutwolf, D. W. M. Arrigan. Ion-Transfer Voltammetric Behavior of Propranolol at Nanoscale Liquid-Liquid Interface Arrays. Analytical Chemistry. 2015, 87, 4487.

[43] T. Ji, Z. Liang, X. Zhu, L. Wang, S. Liu, Y. Shao. Probing the structure of a water/nitrobenzene interface by scanning ion conductance microscopy. Chemical Science. 2011, 2, 1523.

[44] A. J. Bard, L. R. Faulkner. Electrochemical Methods: Fundamentals and Applications 2001 (John Wiley and Sons: New York).

[45] (a) Y. Kim, S. Amemiya. Stripping analysis of nanomolar perchlorate in drinking water with a voltammetric ion-selective electrode based on thin-layer liquid membrane. Analytical Chemistry. 2008, 80, 6056; (b) B. Kabagambe, A. Izadyar, S. Amemiya. Stripping Voltammetry of Nanomolar Potassium and 
Ammonium Ions Using a Valinomycin-Doped Double-Polymer Electrode. Analytical Chemistry. 2012, 84, 7979; (c) B. Kabagambe, M. B. Garada, R. Ishimatsu, S. Amemiya. Subnanomolar Detection Limit of Stripping Voltammetric Ca2+-Selective Electrode: Effects of Analyte Charge and Sample Contamination. Analytical Chemistry. 2014, 86, 7939.

[46] (a) G. A. Crespo, M. Cuartero, E. Bakker. Thin Layer lonophore-Based Membrane for Multianalyte Ion Activity Detection. Analytical Chemistry. 2015, 87, 7729; (b) M. Cuartero, G. A. Crespo, E. Bakker. IonophoreBased Voltammetric Ion Activity Sensing with Thin Layer Membranes. Analytical Chemistry. 2016, 88, 1654. [47] G. A. Crespo, M. G. Afshar, D. Dorokhin, E. Bakker. Thin Layer Coulometry Based on Ion-Exchanger Membranes for Heparin Detection in Undiluted Human Blood. Analytical Chemistry. 2014, 86, 1357.

[48] Y. Saito. A theoretical study on the diffusion current at the stationary electrodes of circular and narrow band types. Rev Polarog (Japan). 1968, 15, 177.

[49] (a) H. J. Lee, P. D. Beattie, B. J. Seddon, M. D. Osborne, H. H. Girault. Amperometric ion sensors based on laser-patterned composite polymer membranes. Journal of Electroanalytical Chemistry. 1997, 440, 73; (b) E. Alvarez de Eulate, J. Strutwolf, Y. Liu, K. O'Donnell, D. W. M. Arrigan. An Electrochemical Sensing Platform Based on Liquid-Liquid Microinterface Arrays Formed in Laser-Ablated Glass Membranes. Analytical Chemistry. 2016.

[50] J. Strutwolf, M. D. Scanlon, D. W. M. Arrigan. Electrochemical ion transfer across liquid/liquid interfaces confined within solid-state micropore arrays - simulations and experiments. Analyst. 2009, 134, 148.

[51] (a) J. Strutwolf, D. W. M. Arrigan. Optimisation of the conditions for stripping voltammetric analysis at liquid-liquid interfaces supported at micropore arrays: a computational simulation. Analytical and Bioanalytical Chemistry. 2010, 398, 1625; (b) J. Strutwolf, M. D. Scanlon, D. W. M. Arrigan. The performance of differential pulse stripping voltammetry at micro-liquid-liquid interface arrays. Journal of Electroanalytical Chemistry. 2010, 641, 7.

[52] C. J. Collins, D. W. M. Arrigan. Ion-Transfer Voltammetric Determination of the $\beta$-Blocker Propranolol in a Physiological Matrix at Silicon Membrane-Based Liquid vertical bar Liquid Microinterface Arrays.

Analytical Chemistry. 2009, 81, 2344.

[53] L. J. Sanchez Vallejo, J. M. Ovejero, R. A. Fernández, S. A. Dassie. Simple Ion Transfer at Liquid|Liquid Interfaces. International Journal of Electrochemistry. 2012, 2012, 34.

[54] A. Molina, E. Laborda, R. G. Compton. Cyclic and Square-Wave Voltammetry at Diffusionally Asymmetric Microscopic and Nanoscopic Liquid-Liquid Interfaces: A Simple Theoretical Approach. Journal of Physical Chemistry C. 2014, 118, 18249.

[55] A. Molina, C. Serna, J. A. Ortuno, J. Gonzalez, E. Torralba, A. Gil. Differential Pulse Voltammetry for Ion Transfer at Liquid Membranes with Two Polarized Interfaces. Analytical Chemistry. 2009, 81, 4220.

[56] X. H. Jiang, K. Gao, D. P. Hu, H. H. Wang, S. J. Bian, Y. Chen. Ion-transfer voltammetric determination of folic acid at meso-liquid-liquid interface arrays. Analyst. 2015, 140, 2823.

[57] M. Velicky, K. Y. Tam, R. A. W. Dryfe. Mechanism of Ion Transfer in Supported Liquid Membrane Systems: Electrochemical Control over Membrane Distribution. Analytical Chemistry. 2014, 86, 435.

[58] (a) O. Shirai, S. Kihara, Y. Yoshida, M. Matsui. Ion transfer through a liquid membrane or a bilayerlipid membrane in the presence of sufficient electrolytes Journal of Electroanalytical Chemistry. 1995, 389, 61; (b) S. M. Ulmeanu, H. Jensen, Z. Samec, G. Bouchard, P. A. Carrupt, H. H. Girault. Cyclic voltammetry of highly hydrophilic ions at a supported liquid membrane. Journal of Electroanalytical Chemistry. 2002, 530, 10.

[59] M. A. Deryabina, S. H. Hansen, H. Jensen. Versatile Flow-Injection Amperometric Ion Detector Based on an Interface between Two Immiscible Electrolyte Solutions: Numerical and Experimental Characterization. Analytical Chemistry. 2011, 83, 7388.

[60] D. P. Hu, H. H. Wang, K. Gao, X. H. Jiang, M. Wang, Y. F. Long, et al. Anion transfer across "anion channels" at the liquid/liquid interface modified by anion-exchange membrane. Rsc Advances. 2014, 4, 57035.

[61] (a) V. Marecek, H. Janchenova. Electrochemically controlled formation of a silicate membrane at a liquid vertical bar liquid interface. Journal of Electroanalytical Chemistry. 2003, 558, 119; (b) L. Poltorak, G. 
Herzog, A. Walcarius. In-situ formation of mesoporous silica films controlled by ion transfer voltammetry at the polarized liquid-liquid interface. Electrochemistry Communications. 2013, 37, 76; (c) L. Poltorak, M.

Dossot, G. Herzog, A. Walcarius. Interfacial processes studied by coupling electrochemistry at the polarised liquid-liquid interface with in situ confocal Raman spectroscopy. Physical Chemistry Chemical Physics. 2014, 16, 26955; (d) L. Poltorak, G. Herzog, A. Walcarius. Electrochemically Assisted Generation of Silica Deposits Using a Surfactant Template at Liquid/Liquid Microinterfaces. Langmuir. 2014, 30, 11453.

[62] J. Koryta. Electrochemical polarization phenomena at the interface of two immiscible electrolyte solutions Electrochimica Acta. 1979, 24, 293.

[63] (a) F. Reymond, P. A. Carrupt, H. H. Girault. Facilitated ion transfer reactions across oil vertical bar water interfaces. Part I. Algebraic development and calculation of cyclic voltammetry experiments for successive complex formation. Journal of Electroanalytical Chemistry. 1998, 449, 49; (b) F. Reymond, G. Lagger, P.-A. Carrupt, H. H. Girault. Facilitated ion transfer reactions across oil| water interfaces: Part II. Use of the convoluted current for the calculation of the association constants and for an amperometric determination of the stoichiometry of MLjz+ complexes. Journal of Electroanalytical Chemistry. 1998, 451, 59.

[64] H. Matsuda, Y. Yamada, K. Kanamori, Y. Kudo, Y. Takeda. On the facilitation effect of neutral macrocyclic ligands on the ion transfer across the interface between aqueous and organic solutions. 1. Theoretical equation of ion transfer polarographic current-potential curves and its experimental verification. Bulletin of the Chemical Society of Japan. 1991, 64, 1497.

[65] R. Ishimatsu, A. Izadyar, B. Kabagambe, Y. Kim, J. Kim, S. Amemiya. Electrochemical Mechanism of Ion-lonophore Recognition at Plasticized Polymer Membrane/Water Interfaces. Journal of the American Chemical Society. 2011, 133, 16300.

[66] (a) G. Girma, L. J. Yu, L. Huang, S. Jin, D. Y. Wu, D. P. Zhan. Alkali metal ions transfer across the water/1,2-dichloroethane interface facilitated by a series of crown ethers. Analytical Methods. 2013, 5, 4666; (b) Y. H. Shao, M. V. Mirkin. Fast kinetic measurements with nanometer-sized pipets. Transfer of potassium ion from water into dichloroethane facilitated by dibenzo-18-crown-6. Journal of the American Chemical Society. 1997, 119, 8103.

[67] Y. H. Qiao, B. Zhang, X. Y. Zhu, T. R. Ji, B. Li, Q. Li, et al. Facilitated Ion Transfers at the MicroWater/1,2-Dichloroethane Interface by Crown Ether Derivatives. Electroanalysis. 2013, 25, 1080.

[68] (a) D. P. Zhan, S. N. Mao, Q. Zhao, Z. Chen, H. Hu, P. Jing, et al. Electrochemical investigation of dopamine at the water/1,2-dichloroethane interface. Analytical Chemistry. 2004, 76, 4128; (b) D. W. M. Arrigan, M. Ghita, V. Beni. Selective voltammetric detection of dopamine in the presence of ascorbate. Chemical Communications. 2004, 732; (c) J. A. Ribeiro, I. M. Miranda, F. Silva, C. M. Pereira. Electrochemical study of dopamine and noradrenaline at the water/1,6-dichlorohexane interface. Physical Chemistry Chemical Physics. 2010, 12, 15190.

[69] Y. Chen, Y. Yuan, M. Q. Zhang, F. Li, P. Sun, Z. Gao, et al. Systematic study of the transfer of amino acids across the water/1,2-dichloroethane interface facilitated by dibenzo-18-crown- 6 . Science in China Series B-Chemistry. 2004, 47, 24.

[70] J. Wickens, R. A. W. Dryfe, F. S. Mair, R. G. Pritchard, R. Hayes, D. W. M. Arrigan. Calixarenefacilitated transfer of alkali metal ions across the polarised liquid-liquid interface. New Journal of Chemistry. 2000, 24, 149.

[71] (a) J. Zhang, A. R. Harris, R. W. Cattrall, A. M. Bond. Voltammetric lon-Selective Electrodes for the Selective Determination of Cations and Anions. Analytical Chemistry. 2010, 82, 1624; (b) A. R. Harris, J.

Zhang, R. W. Cattrall, A. M. Bond. Applications of voltammetric ion selective electrodes to complex matrices. Analytical Methods. 2013, 5, 3840.

[72] M. Ghahraman Afshar, G. A. Crespo, E. Bakker. Counter electrode based on an ion-exchanger Donnan exclusion membrane for bioelectroanalysis. Biosensors and Bioelectronics. 2014, 61, 64.

[73] G. A. Crespo, E. Bakker. Dynamic electrochemistry with ionophore based ion-selective membranes. RSC Advances. 2013, 3, 25461.

[74] U. Nestor, H. M. Wen, G. Girma, Z. Q. Mei, W. K. Fei, Y. Yang, et al. Facilitated Lit ion transfer across the water/1,2-dichloroethane interface by the solvation effect. Chemical Communications. 2014, 50, 1015. 
[75] C. M. Pereira, N. Tirilly, M. C. Martins, F. Silva. Development of Zn(II) sensors based on the assisted transfer of metal ions by hydrophobic ligands through gel-supported microinterfaces. Fresenius Journal of Analytical Chemistry. 2001, 369, 609.

[76] S. H. Lee, J. Sumranjit, P. Tongkate, B. H. Chung, H. J. Lee. Voltammetric Studies of Cu(II) Ion Transfer Reaction with Picolinamide-phenylenevinylene across Liquid/liquid Interfaces and Their Sensing Applications. Electrochimica Acta. 2014, 123, 198.

[77] H. Bingol, T. Atalay. Interfacial transfer of $\mathrm{Cd} 2+$ assisted by 4 '-morpholino-acetophenone-4-phenyl3-thiosemicarbazone across the water/1,2-dichloroethane interface. Central European Journal of Chemistry. 2010, 8, 1132.

[78] C. M. Pereira, J. M. Oliveira, R. M. Silva, F. Silva. Amperometric glucose biosensor based on assisted ion transfer through gel-supported microinterfaces. Analytical Chemistry. 2004, 76, 5547.

[79] M. M. Hossain, S. N. Faisal, C. S. Kim, H. J. Cha, S. C. Nam, H. J. Lee. Amperometric proton selective strip-sensors with a microelliptic liquid/gel interface for organophosphate neurotoxins. Electrochemistry Communications. 2011, 13, 611.

[80] F. Kivlehan, W. J. Mace, H. A. Moynihan, D. W. M. Arrigan. Potentiometric evaluation of calix[4]arene anion receptors in membrane electrodes: Phosphate detection. Analytica Chimica Acta. 2007, 585, 154.

[81] S. Nishizawa, T. Yokobori, R. Kato, K. Yoshimoto, T. Kamaishi, N. Teramae. Hydrogen-bond forming ionophore for highly efficient transport of phosphate anions across the nitrobenzene-water interface. Analyst. 2003, 128, 663.

[82] R. F. Cui, Q. Li, D. E. Gross, X. Meng, B. Li, M. Marquez, et al. Anion Transfer at a Micro-Water/1,2Dichloroethane Interface Facilitated by beta-Octafluoro-meso-octamethylcalix 4 pyrrole. Journal of the American Chemical Society. 2008, 130, 14364.

[83] R. A. W. Dryfe, S. S. Hill, A. P. Davis, J. B. Joos, E. P. L. Roberts. Electrochemical quantification of highaffinity halide binding by a steroid-based receptor. Organic \& Biomolecular Chemistry. 2004, 2, 2716.

[84] P. D. Beer, P. A. Gale. Anion recognition and sensing: The state of the art and future perspectives. Angew Chem-Int Edit. 2001, 40, 486.

[85] P. Bühlmann, L. D. Chen. in Supramolecular Chemistry 2012, (John Wiley \& Sons, Ltd).

[86] P. Buhlmann, E. Pretsch, E. Bakker. Carrier-based ion-selective electrodes and bulk optodes. 2. Ionophores for potentiometric and optical sensors. Chemical Reviews. 1998, 98, 1593.

[87] (a) R. A. W. Dryfe, S. M. Holmes. Zeolitic rectification of electrochemical ion transfer. Journal of Electroanalytical Chemistry. 2000, 483, 144; (b) R. A. W. Dryfe. Modifying the liquid/liquid interface: pores, particles and deposition. Physical Chemistry Chemical Physics. 2006, 8, 1869.

[88] C. I. Camara, C. A. Bornancini, J. L. Cabrera, M. G. Ortega, L. M. Yudi. Quantitative analysis of boldine alkaloid in natural extracts by cyclic voltammetry at a liquid-liquid interface and validation of the method by comparison with high performance liquid chromatography. Talanta. 2010, 83, 623.

[89] D. W. M. Arrigan. Bioanalytical Detection Based on Electrochemistry at Interfaces between Immiscible Liquids. Analytical Letters. 2008, 41, 3233.

[90] (a) C. J. Collins, A. Berduque, D. W. M. Arrigan. Electrochemically Modulated Liquid-Liquid Extraction of Ionized Drugs under Physiological Conditions. Analytical Chemistry. 2008, 80, 8102; (b) C. J. Collins, C. Lyons, J. Strutwolf, D. W. M. Arrigan. Serum-protein effects on the detection of the beta-blocker propranolol by ion-transfer voltammetry at a micro-ITIES array. Talanta. 2010, 80, 1993; (c) S. Fantini, J. Clohessy, K. Gorgy, F. Fusalba, C. Johans, K. Kontturi, et al. Influence of the presence of a gel in the water phase on the electrochemical transfer of ionic forms of beta-blockers across a large water vertical bar 1,2-dichloroethane interface. European Journal of Pharmaceutical Sciences. 2003, 18, 251.

[91] P. Lopes, R. Kataky. Chiral Interactions of the Drug Propranolol and alpha(1)-Acid-Glycoprotein at a Micro Liquid-Liquid Interface. Analytical Chemistry. 2012, 84, 2299.

[92] H. R. Kim, C. M. Pereira, H. Y. Han, H. J. Lee. Voltammetric Studies of Topotecan Transfer Across Liquid/Liquid Interfaces and Sensing Applications. Analytical Chemistry. 2015, 87, 5356.

[93] (a) J. A. Ribeiro, F. Silva, C. M. Pereira. Electrochemical Study of the Anticancer Drug Daunorubicin at a Water/Oil Interface: Drug Lipophilicity and Quantification. Analytical Chemistry. 2013, 85, 1582; (b) J. A. 
Ribeiro, C. M. Pereira, F. Silva. Electrochemistry of the Interaction between Bioactive Drugs Daunorubicin and Dopamine and DNA at a Water/Oil Interface. Electrochimica Acta. 2015, 180, 687.

[94] (a) V. Beni, M. Ghita, D. W. M. Arrigan. Cyclic and pulse voltammetric study of dopamine at the interface between two immiscible electrolyte solutions. Biosensors \& Bioelectronics. 2005, 20, 2097; (b) 0. Dvorak, V. Marecek, Z. Samec. Selective complexation of biogenic amines by macrocyclic polyethers at a liquid-liquid interface Journal of Electroanalytical Chemistry. 1991, 300, 407; (c) D. Homolka, V. Marecek, Z. Samec, K. Base, H. Wendt. The partition of amines between water and an organic solvent phase Journal of Electroanalytical Chemistry. 1984, 163, 159.

[95] J. A. Ribeiro, F. Silva, C. M. Pereira. Electrochemical Sensing of Catecholamines at the Water/1,6Dichlorohexane Interface. Electroanalysis. 2013, 25, 2331.

[96] E. Torralba, J. A. Ortuno, A. Molina, C. Serna, F. Karimian. Facilitated ion transfer of protonated primary organic amines studied by square wave voltammetry and chronoamperometry. Analytica Chimica Acta. 2014, 826, 12.

[97] A. Izadyar, D. R. Arachchige, H. Cornwell, J. C. Hershberger. Ion transfer stripping voltammetry for the detection of nanomolar levels of fluoxetine, citalopram, and sertraline in tap and river water samples. Sensors and Actuators B: Chemical. 2016, 223, 226.

[98] M. L. Colombo, J. V. Sweedler, M. Shen. Nanopipet-Based Liquid-Liquid Interface Probes for the Electrochemical Detection of Acetylcholine, Tryptamine, and Serotonin via Ionic Transfer. Analytical Chemistry. 2015, 87, 5095.

[99] M. L. Colombo, S. McNeil, N. Iwai, A. Chang, M. Shen. Electrochemical Detection of Dopamine via Assisted Ion Transfer at Nanopipet Electrode Using Cyclic Voltammetry. Journal of The Electrochemical Society. 2016, 163, H3072.

[100] G. Herzog, D. W. M. Arrigan. Electrochemical strategies for the label-free detection of amino acids, peptides and proteins. Analyst. 2007, 132, 615.

[101] P. Vanysek, J. D. Reid, M. A. Craven, R. P. Buck. Properties of the interface between two immiscible electrolytes in the presence of proteins Journal of the Electrochemical Society. 1984, 131, 1788.

[102] M. A. Mendez, Z. Nazemi, I. Uyanik, Y. Lu, H. H. Girault. Melittin Adsorption and Lipid Monolayer Disruption at Liquid-Liquid Interfaces. Langmuir. 2011, 27, 13918.

[103] E. Alvarez de Eulate, S. O'Sullivan, S. Fletcher, P. Newsholme, D. W. M. Arrigan. Ion-Transfer Electrochemistry of Rat Amylin at the Water-Organogel Microinterface Array and Its Selective Detection in a Protein Mixture. Chemistry-an Asian Journal. 2013, 8, 2096.

[104] (a) S. Amemiya, X. T. Yang, T. L. Wazenegger. Voltammetry of the phase transfer of polypeptide protamines across polarized liquid/liquid interfaces. Journal of the American Chemical Society. 2003, 125, 11832; (b) Y. Yuan, S. Amemiya. Facilitated protamine transfer at polarized water/1,2-dichloroethane interfaces studied by cyclic voltammetry and chronoamperometry at micropipet electrodes. Analytical Chemistry. 2004, 76, 6877; (c) A. Trojanek, J. Langmaier, E. Samcova, Z. Samec. Counterion binding to protamine polyion at a polarised liquid-liquid interface. Journal of Electroanalytical Chemistry. 2007, 603, 235; (d) M. B. Garada, B. Kabagambe, S. Amemiya. Extraction or Adsorption? Voltammetric Assessment of Protamine Transfer at lonophore-Based Polymeric Membranes. Analytical Chemistry. 2015, 87, 5348. [105] (a) F. Kivlehan, Y. H. Lanyon, D. W. M. Arrigan. Electrochemical study of insulin at the polarized liquid-liquid interface. Langmuir. 2008, 24, 9876; (b) A. E. Thomsen, H. Jensen, L. Jorgensen, M. van de Weert, J. Ostergaard. Studies on human insulin adsorption kinetics at an organic-aqueous interface determined using a label-free electroanalytical approach. Colloids and Surfaces B-Biointerfaces. 2008, 63, 243; (c) S. O'Sullivan, E. A. de Eulate, Y. H. Yuen, E. Helmerhorst, D. W. M. Arrigan. Stripping voltammetric detection of insulin at liquid-liquid microinterfaces in the presence of bovine albumin. Analyst. 2013, 138, 6192.

[106] S. O'Sullivan, D. W. M. Arrigan. Electrochemical behaviour of myoglobin at an array of microscopic liquid-liquid interfaces. Electrochimica Acta. 2012, 77, 71.

[107] (a) G. C. Lillie, S. M. Holmes, R. A. W. Dryfe. Electrochemistry of cytochrome $c$ at the liquid-liquid interface. Journal of Physical Chemistry B. 2002, 106, 12101; (b) Y. Imai, T. Sugihara, T. Osakai. Electron Transfer Mechanism of Cytochrome $c$ at the Oil/Water Interface as a Biomembrane Model. Journal of 
Physical Chemistry B. 2012, 116, 585; (c) S. O'Sullivan, D. W. M. Arrigan. Impact of a Surfactant on the Electroactivity of Proteins at an Aqueous-Organogel Microinterface Array. Analytical Chemistry. 2013, 85, 1389; (d) T. Osakai, A. Shinohara. Electrochemical aspects of the reverse micelle extraction of proteins. Analytical Sciences. 2008, 24, 901; (e) T. Osakai, Y. Yuguchi, E. Gohara, H. Katano. Direct Label-free Electrochemical Detection of Proteins Using the Polarized Oil/Water Interface. Langmuir. 2010, 26, 11530. [108] (a) M. D. Scanlon, E. Jennings, D. W. M. Arrigan. Electrochemical behaviour of hen-egg-white lysozyme at the polarised water/1,2-dichloroethane interface. Physical Chemistry Chemical Physics. 2009, 11, 2272; (b) E. Alvarez de Eulate, D. W. M. Arrigan. Adsorptive Stripping Voltammetry of Hen-Egg-WhiteLysozyme via Adsorption-Desorption at an Array of Liquid-Liquid Microinterfaces. Analytical Chemistry. 2012, 84, 2505; (c) E. Alvarez de Eulate, D. S. Silvester, D. W. M. Arrigan. Behavior of Lysozyme at the Electrified Water/Room Temperature Ionic Liquid Interface. Chemistry - An Asian Journal. 2012, 7, 2559; (d) M. G. Chernysheva, O. A. Soboleva, G. A. Badun. Competitive adsorption and interactions between lysozyme and ionic surfactants in an aqueous/organic liquid system. Colloids and Surfaces a-Physicochemical and Engineering Aspects. 2012, 409, 130; € E. Alvarez de Eulate, L. Qiao, M. D. Scanlon, H. H. Girault, D. W. M. Arrigan. Fingerprinting the tertiary structure of electroadsorbed lysozyme at soft interfaces by electrostatic spray ionization mass spectrometry. Chemical Communications. 2014, 50, 11829; (f) B. M. B. Felisilda, E. Alvarez de Eulate, D. W. M. Arrigan. Investigation of a solvent-cast organogel to form a liquid-gel microinterface array for electrochemical detection of lysozyme. Analytica Chimica Acta. 2015, 893, 34; (g) M. D. Scanlon, J. Strutwolf, D. W. M. Arrigan. Voltammetric behaviour of biological macromolecules at arrays of aqueous vertical bar organogel micro-interfaces. Physical Chemistry Chemical Physics. 2010, 12, 10040.

[109] (a) G. Herzog, V. Kam, D. W. M. Arrigan. Electrochemical behaviour of haemoglobin at the liquid/liquid interface. Electrochimica Acta. 2008, 53, 7204; (b) G. Herzog, W. Moujahid, J. Strutwolf, D. W. M. Arrigan. Interactions of proteins with small ionised molecules: electrochemical adsorption and facilitated ion transfer voltammetry of haemoglobin at the liquid vertical bar liquid interface. Analyst. 2009, 134, 1608; (c) E. Alvarez de Eulate, L. Serls, D. M. Arrigan. Detection of haemoglobin using an adsorption approach at a liquid-liquid microinterface array. Analytical and Bioanalytical Chemistry. 2012, 1.

[110] P. Vanysek, Z. S. Sun. Bovine serum albumin adsorption on a water - nitrobenzene interface Bioelectrochemistry and Bioenergetics. 1990, 23, 177.

[111] T. Osakai, T. Hirai, T. Wakamiya, S. Sawada. Quantitative analysis of the structure-hydrophobicity relationship for di- and tripeptides based on voltammetric measurements with an oil/water interface. Physical Chemistry Chemical Physics. 2006, 8, 985.

[112] G. Herzog, S. Flynn, C. Johnson, D. W. M. Arrigan. Electroanalytical Behavior of Poly-L-Lysine Dendrigrafts at the Interface between Two Immiscible Electrolyte Solutions. Analytical Chemistry. 2012, 84, 5693.

[113] M. Shinshi, T. Sugihara, T. Osakai, M. Goto. Electrochemical extraction of proteins by reverse micelle formation (vol 22, pg 5937, 2006). Langmuir. 2006, 22, 8614.

[114] T. Osakai, H. Komatsu, M. Goto. Cationic-surfactant transfer facilitated by DNA adsorbed on a polarized 1,2-dichloroethane/water interface. Journal of Physics-Condensed Matter. 2007, 19.

[115] (a) Z. Samec, A. Trojanek, J. Langmaier, E. Samcova. Cyclic voltammetry of biopolymer heparin at PVC plasticized liquid membrane. Electrochemistry Communications. 2003, 5, 867; (b) J. D. Guo, Y. Yuan, S. Amemiya. Voltammetric detection of heparin at polarized blood plasma/1,2-dichloroethane interfaces. Analytical Chemistry. 2005, 77, 5711; (c)J. D. Guo, S. Amemiya. Voltammetric heparin-selective electrode based on thin liquid membrane with conducting polymer-modified solid support. Analytical Chemistry. 2006, 78, 6893; (d) S. Amemiya, Y. Kim, R. Ishimatsu, B. Kabagambe. Electrochemical heparin sensing at liquid/liquid interfaces and polymeric membranes. Analytical and Bioanalytical Chemistry. 2011, 399, 571.

[116] (a) J. Langmaier, J. Olsak, E. Samcova, Z. Samec, A. Trojanek. Amperometry of heparin polyion using a rotating disk electrode coated with a plasticized PVC membrane. Electroanalysis. 2006, 18, 115; (b) J.

Langmaier, J. Olsak, E. Samcova, Z. Samec, A. Trojanek. Amperometric sensor for heparin: Sensing mechanism and application in human blood plasma analysis. Electroanalysis. 2006, 18, 1329; (c) J. Langmaier, Z. Samec, E. Samcova, P. Tuma. Transfer of heparin polyion across a polarized water/ionic liquid membrane interface. Electrochemistry Communications. 2012, 24, 25. 
[117] D. S. Silvester, D. W. M. Arrigan. Array of water vertical bar room temperature ionic liquid microinterfaces. Electrochemistry Communications. 2011, 13, 477.

[118] G. Herzog, A. Roger, D. Sheehan, D. W. M. Arrigan. Ion-transfer voltammetric behavior of protein digests at liquid - liquid interfaces. Analytical Chemistry. 2010, 82, 258. 